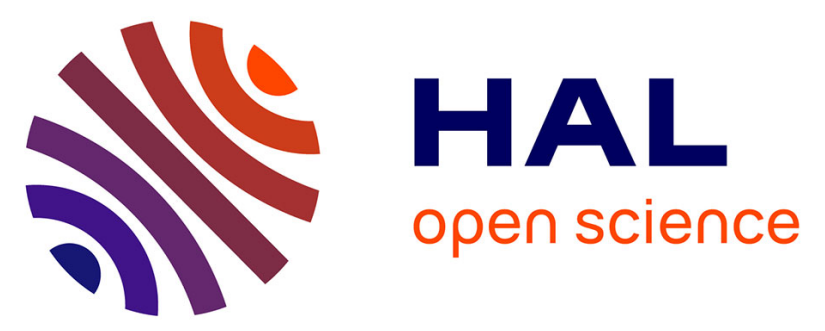

\title{
Nano-thermometers with thermo-sensitive polymer grafted USPIOs behaving as positive contrast agents in low-field MRI
}

\author{
Adeline Hannecart, Dimitri Stanicki, Luce Vander Elst, Robert N. Muller,
} Sébastien Lecommandoux, Julie Thevenot, Colin Bonduelle, Aurelien Trotier, Philippe Massot, Sylvain Miraux, et al.

\section{To cite this version:}

Adeline Hannecart, Dimitri Stanicki, Luce Vander Elst, Robert N. Muller, Sébastien Lecommandoux, et al.. Nano-thermometers with thermo-sensitive polymer grafted USPIOs behaving as positive contrast agents in low-field MRI. Nanoscale, 2015, 7 (8), pp.3754-3767. 10.1039/c4nr07064j . hal01361815

\section{HAL Id: hal-01361815 https://hal.science/hal-01361815}

Submitted on 3 Nov 2018

HAL is a multi-disciplinary open access archive for the deposit and dissemination of scientific research documents, whether they are published or not. The documents may come from teaching and research institutions in France or abroad, or from public or private research centers.
L'archive ouverte pluridisciplinaire HAL, est destinée au dépôt et à la diffusion de documents scientifiques de niveau recherche, publiés ou non, émanant des établissements d'enseignement et de recherche français ou étrangers, des laboratoires publics ou privés. 


\title{
Nano-thermometer with Thermo-sensitive Polymer Grafted USPIOs behaving as Positive Contrast Agents in low-field MRI
}

\author{
Adeline Hannecart, ${ }^{a}$ Dimitri Stanicki, ${ }^{a}$ Luce Vander Elst,,${ }^{a, b}$ Robert N. Muller, ${ }^{a, b}$ Sébastien \\ Lecommandoux, ${ }^{c}$ Julie Thévenot, ${ }^{c}$ Colin Bonduelle, ${ }^{c}$ Aurélien Trotier, ${ }^{d}$ Philippe Massot, ${ }^{d}$ Sylvain \\ ${ }_{5}$ Miraux ${ }^{d}$ Olivier Sandre, ${ }^{* c}$ and Sophie Laurent ${ }^{* a, b}$
}

Received $29^{\text {th }}$ November 2014, Accepted $19^{\text {th }}$ January 2015

DOI: $10.1039 /$ C4NR07064J

Two commercial statistical copolymers of ethylene oxide and propylene oxide, Jeffamine ${ }^{\circledR} \mathrm{M}-2005$ $\left(\mathrm{PEO}_{5}\right.$-st- $\left.\mathrm{PPO}_{37}\right)$ and $\mathrm{M}-2070\left(\mathrm{PEO}_{46}\right.$-st-PPO $\left.{ }_{13}\right)$, exhibiting lower critical solution temperature (LCST) in

10 water, were grafted onto the surface of ultra-small superparamagnetic iron oxide nanoparticles (USPIOs) using silanization and amide-bond coupling reactions. The LCSTs of the polymers in solution were measured by dynamic light scattering (DLS) and nuclear magnetic resonance (NMR). In accordance with the compositions of EO $v$ s. PO, the transition temperature was measured at $22 \pm 2{ }^{\circ} \mathrm{C}$ for $\mathrm{M}-2005$ both by DLS and NMR, while the LCST was much higher, $52 \pm 2^{\circ} \mathrm{C}$, for M-2070 (a second transition being also

15 detected above $80^{\circ} \mathrm{C}$ by NMR in that case, ascribed to the full dehydration of chains at molecular level). The resulting polymer-grafted USPIOs exhibit a temperature-responsive colloidal behaviour, their surface reversibly changing from hydrophilic below LCST to hydrophobic above it. This phenomenon was utilised to design thermo-sensitive contrast agents for MRI. Transverse relaxivities $\left(r_{2}\right)$ of the USPIO@PEO -st-PPO $_{37}$ core-shell nanoparticles were measured at 8.25, 20,60, and $300 \mathrm{MHz}$. Nuclear 20 magnetic resonance dispersion (NMRD) profiles, giving longitudinal relaxivities $\left(r_{1}\right)$ between 0.01 and 60 $\mathrm{MHz}$, were acquired at temperatures ranging from 15 to $50^{\circ} \mathrm{C}$. For all tested frequencies except $300 \mathrm{MHz}$, both $r_{1}$ and $r_{2}$ decrease with temperature and show an inflection point at $25^{\circ} \mathrm{C}$, near the LCST. To illustrate the interest of such polymer-coated USPIOs for MRI thermometry, sample tubes were imaged on both low-field (8.25 MHz/0.194 Tesla) and high-field (300 MHz / 7.05 Tesla) MRI scanners with ${ }_{25}$ either $T_{1}$ - or $T_{2}{ }^{*}$-weighted spin echo sequences. The positive contrast on low-field MR images and the perfect linearity of the signal with a $T_{2}{ }^{*}$-weighted sequence over the whole temperature range $15^{\circ} \mathrm{C}-$ $50^{\circ} \mathrm{C}$ render these LCST polymer coated USPIOs interesting positive contrast agents, also working as "nano-thermometers".

\section{Introduction}

30 Superparamagnetic iron oxide nanoparticles are widely studied due to their unique properties such as high magnetisation, biocompatibility and biodegradability. ${ }^{1}$ Their main biomedical application is their use as contrast agents for magnetic resonance imaging (MRI). ${ }^{2}$ Iron oxide nanoparticles lead to a MRI contrast 35 enhancement by accelerating the relaxation of magnetic moments of water protons. The efficiency of a MRI contrast agent is quantified by its relaxivities $r_{1}$ and $r_{2}$, defined as the increases of the proton nuclear relaxation rates $1 / T_{1}$ and $1 / T_{2}$ of the solvent brought by one millimole of equivalent iron per liter $\left(\mathrm{s}^{-1} \cdot \mathrm{mM}_{\mathrm{Fe}}{ }^{-1}\right)$, 40 respectively for longitudinal $\left(r_{1}\right)$ and transverse $\left(r_{2}\right)$ relaxations. Superparamagnetic iron oxide nanoparticles are divided into ultra-small (USPIO) monocrystalline cores with hydrodynamic diameters $\left(D_{\mathrm{h}}\right)$ below $40 \mathrm{~nm}$ and polycrystalline clusters denoted SPIOs. The clustering of several magnetic cores usually leads to a ${ }_{45}$ high $r_{2} / r_{1}$ ratio that can reach values up to several hundred depending on magnetic field (Larmor frequency) of the MRI scanner. Thus SPIOs are mostly used with $T_{2}$ or $T_{2}{ }^{*}$-weighted MR pulse sequences, introducing a "negative contrast" on images, i.e. appearing darker than the pure buffer or tissue. However, very 50 small diameter USPIOs maintaining a low $r_{2} / r_{1}$ ratio (typically less than 3-4) can also act as "positive contrast agents" (appearing brighter than pure water) as long as they stay individually dispersed in the suspension, i.e. their hydrodynamic diameters remain low, e.g. $D_{\mathrm{h}}<20 \mathrm{~nm} .^{3,4}$ This implies that not only magnetic ${ }_{55}$ cores are small, but also that they are protected from aggregation by a repulsive shell. This stabilising coating can be made of the hydrophilic biocompatible polymer poly(ethyleneglycol) either as a homopolymer ${ }^{3}$ or a copolymer block, ${ }^{4}$ but other biopolymers like glycopolypeptides were also reported to prevent clustering 60 and obtain efficient positive $\left(T_{1}\right)$ contrast agents. ${ }^{\mathbf{5}}$

To grow a dense polymer brush at the surface of USPIOs, a "grafting on" technique is usually preferred to simple polymer adsorption, which rather leads to multi-core clusters generating 
hypo-signals on MR images like for the commercial negative $\left(T_{2}\right)$ contrast agent Endorem ${ }^{\circledR}$. Thus one needs first to introduce functions for further coupling reactions, by grafting covalently a monolayer of short and densely packed organic molecules such as s (3-aminopropyl)triethoxysilane (APTS), a molecule frequently used in the literature to introduce amino groups. ${ }^{\mathbf{5 , 6}}$ Instead of working on bare hydrophilic USPIOs, certain studies start with a ligand-organosilane exchange on hydrophobic USPIOs initially coated by oleic acid. ${ }^{\mathbf{7} 8}$ Even though the surface modification of 10 iron oxide nanoparticles with APTS only is not sufficient to achieve colloidal stability at $\mathrm{pH} 7$ in high salinity buffers, it is often a first step to further functionalise the USPIOs with longer molecules. ${ }^{\mathbf{5 , 6}}$ Other functionalities were introduced by grafting organosilanes at the surface of USPIOs for various coupling 15 reactions, like epoxide ${ }^{4}$ or cyanide ${ }^{9}$, or a brominated endgroup as initiator for controlled radical polymerisation. ${ }^{8}$

Besides preventing aggregation of the USPIOs, the presence of a non-magnetic shell wrapping the magnetic cores can also directly influence the $r_{1}$ and $r_{2}$ relaxivities if it is impermeable to 20 water. For example, a significant decrease of $r_{1}$ and $r_{2}$ with the coating thickness was observed for silica shells synthesised by a sol-gel method. ${ }^{10}$ On the contrary, a highly hydrated shell around densely clustered USPIOs like in magnetic hydrogels can greatly enhance the $r_{2}$ relaxivity up to $500-600 \mathrm{~s}^{-1} \cdot \mathrm{mM}_{\mathrm{Fe}}{ }^{-1} \cdot{ }^{11}$ The so25 called "outer sphere" model describes all these behaviours and enables predicting the $r_{2}$ value in the high field of most clinical imagers through a unified scaling law with three parameters only: the distance of closest approach between water protons and the centre of the superparamagnetic particle $\left(R_{\mathrm{NMR}}\right)$, the intra-particle 30 volume fraction of magnetic materials ( $\left.\Phi_{\text {intra }}\right)$ and the magnetisation (defined as the volume concentration of magnetic moments) at saturation $\left(M_{\mathrm{S}}\right)$ of the whole sphere: ${ }^{12}$

$$
r_{2} \cdot \Phi_{\text {intra }}=\gamma^{2} \mu_{0}^{2} v_{\text {mol }}\left(M_{\mathrm{S}} \cdot R_{\mathrm{NMR}}\right)^{2} / 405 D
$$

$\gamma \approx 2.67513 \times 10^{8} \mathrm{rad} \cdot \mathrm{s}^{-1} \cdot \mathrm{T}^{-1}$ being the proton gyromagnetic factor, ${ }_{35} \mu_{0}=4 \pi 10^{-7} \mathrm{~T} \cdot \mathrm{m} \cdot \mathrm{A}^{-1}$ the magnetic permeability of vacuum, $D$ the diffusion constant of water molecules, and $v_{\text {mol }}$ the specific volume of the magnetic material, $\sim 15.7 \mathrm{~cm}^{3} \cdot \mathrm{mol}^{-1}$ for iron oxide. This formula is valid only in the so-called "Motional Averaging Regime", i.e. in a limited range of size and magnetisation values.

40 Above this limit, the transverse relaxivity reaches a maximum described by the "Static Dephasing Regime" that cannot be easily compared to experimental data without the use of numerical simulations. $^{\mathbf{1 2}}$

This work reports the grafting of thermo-sensitive Jeffamine ${ }^{\circledR}$ 45 M-2005 and M-2070 onto the surface of iron oxide nanoparticles. Jeffamine ${ }^{\circledR}$ products are amino-terminated statistical copolymers of ethylene oxide (EO) and propylene oxide (PO) units. These commercial poly(ether)amines exhibit a lower critical solution temperature (LCST) in water: soluble in water below the LCST, ${ }_{50}$ they undergo a reversible coil-to-globule transition at the LCST and become insoluble at temperatures above the LCST. ${ }^{\mathbf{1 3}}$ Several systems proposed in the literature took benefit of both this temperature-dependant water solubility of Jeffamine ${ }^{\circledR}$ and of its primary amine end-group, enabling further functionalisation. ${ }_{55}$ Block copolymers of Jeffamine ${ }^{\circledR} \mathrm{M}-2005$ with a polypeptide ${ }^{14}$ or a polysaccharide ${ }^{15}$ are soluble in water below the LCST and form self-assembled structures above it. Co-adsorption onto magnetic core-silica shell nanoparticles of a diblock copolymer of Jeffamine $^{\circledR}$ M-2005 with poly $(L$-lysine) (PLL) and PLL- $b$-PEO 60 enabled forming a polymer corona eliciting a LCST tuneable by the PO content. ${ }^{16}$ In another study, M-1000, M-2070 and M-2005 Jeffamine $^{\circledR}$ poly(ether)monoamines were grafted onto carboxylated cellulose nanocrystals by amide bond formation. ${ }^{17}$

The grafting of Jeffamine ${ }^{\circledR}$ onto iron oxide nanoparticles was 65 also described, using epoxide ring opening by the primary amine group of M-1000 and M-2070. ${ }^{4}$ The resulting polymer brushes around the USPIOs were dense and repulsive, and provided good colloidal stability to the nanocrystals, as shown by their positive contrast agent behaviour on MRI images, ${ }^{4}$ ascribed to a low $r_{2} / r_{1}$ 70 ratio. The longitudinal and transverse relaxivities were reported in this work, but not their variation with temperature, presumably because M-1000 and M-2070 are very hydrophilic (their LCST is too high). On the contrary, the higher PO content of M-2005 ensures that its LCST is just above room temperature. Therefore 75 it is well adapted to study how $r_{1}$ and $r_{2}$ relaxivities of iron oxide nanoparticles vary when their surface changes from hydrophilic to hydrophobic, for a given magnetic core size and magnetisation.

The effect of a thermo-sensitive polymer coating on the proton relaxivities of USPIOs was reported in literature in the case of ${ }_{80}$ poly( $N$-isopropylacryamide) (PNIPAM), a widely used polymer with a LCST of $32^{\circ} \mathrm{C}$. At $60 \mathrm{MHz}, r_{1}$ decreased above the LCST whereas $r_{2}$ increased, so that $r_{2} / r_{1}$ increased a lot, as a result of USPIOs' clustering when their coating became hydrophobic. ${ }^{\mathbf{2 2}}$ In a control experiment with a purely hydrophilic PEO coating, $r_{2}$ ${ }_{85}$ decreased and $r_{1}$ remained almost constant as temperature rose. ${ }^{22}$ In another work on USPIOs dispersed in water through a bilayer of surfactants (thus impermeable to water), a similar rather weak variation of $r_{1}$ with temperature was described (with a slope whose sign was dependent upon USPIOs' size), whereas the trend 90 of $r_{2}$ when raising temperature was always a strong decrease. ${ }^{23}$

The present work aims at deciphering the effect of a polymer corona dehydration above LCST on $r_{1}$ and $r_{2}$ as sketched on Scheme 1, while keeping the USPIOs in a dispersed state (thus a low $r_{2} / r_{1}$ ratio), and examining the results on the MR images with ${ }_{95} T_{1}$-weighted and $T_{2}{ }^{*}$-weighted spin echo sequences.

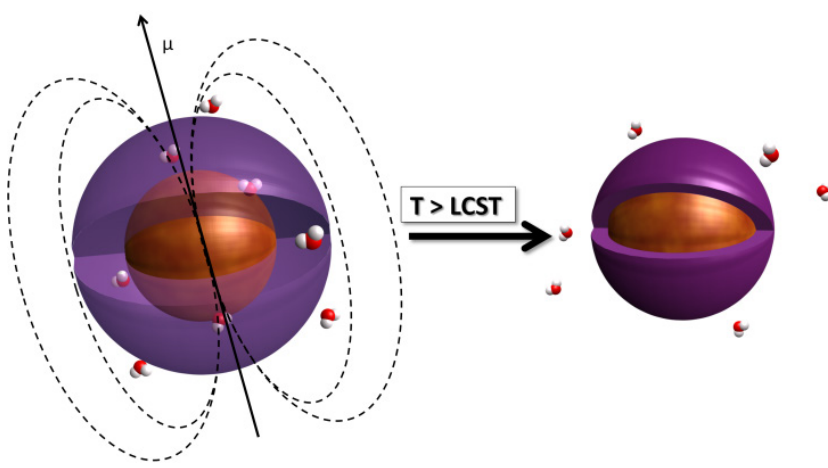

Scheme 1 Sketch of an ultrasmall superparamagnetic iron oxide (USPIO) core wrapped by a thermo-sensitive polymer shell (in purple) highly

hydrated below the LCST that becomes impermeable to water molecules 100 above it. The magnetic moment $\mu$ and the field lines are also represented.

\section{Experimental Section}

\section{Synthesis of iron oxide nanoparticles}

Iron oxide nanoparticles were synthesised in high temperature 
polyol medium by alkaline coprecipitation of $\mathrm{FeCl}_{2}$ and $\mathrm{FeCl}_{3}$ under optimised parameters. ${ }^{18} \mathrm{~A}$ mixture of $\mathrm{FeCl}_{2}(45 \mathrm{mmol})$ and $\mathrm{FeCl}_{3}(37 \mathrm{mmol})\left(n \mathrm{Fe}^{\mathrm{II}} / n \mathrm{Fe}^{\mathrm{III}}=1.22\right)$ in diethyleneglycol $(250 \mathrm{~mL})$ was first mixed $(150 \mathrm{rpm})$ and heated at $170^{\circ} \mathrm{C}$ under nitrogen 5 flux $\left(1.5 \mathrm{~mL} \cdot \mathrm{min}^{-1}\right)$. After $15 \mathrm{~min}, \mathrm{NaOH}(15 \mathrm{~g})$ was added to the medium, which was stirred during $1 \mathrm{~h}$ at $170^{\circ} \mathrm{C}$. After cooling to room temperature, the black precipitate was isolated from the solution by magnetic decantation and washed five times with $\mathrm{HNO}_{3} 1 \mathrm{M}(200 \mathrm{~mL})$. After readily dispersion of the nanoparticles 10 in $100 \mathrm{~mL}$ of de-ionised (DI) water, the suspension was stirred overnight. Finally, the magnetite nanoparticles were sonicated for $45 \mathrm{~min}$ and centrifugated at $16770 \mathrm{~g}$ for $45 \mathrm{~min}$ to pellet any undispersed solid.

\section{Surface functionalisation with carboxylic groups}

15 The iron oxide nanoparticles were functionalised by reaction of their surface hydroxyls with 3-triethoxysilylpropyl succinic anhydride (TEPSA), an organosilane used as precursor of carboxylic acids. Briefly, $50 \mathrm{~mL}$ of DMF was added to $20 \mathrm{~mL}$ of the aqueous suspension of nanoparticles ( $\sim 16 \mathrm{mmol}$ iron). Water 20 was then eliminated by evaporation under reduced pressure. After cooling to room temperature, $4.3 \mathrm{~mL}$ of $\mathrm{DI}$ water, $7.1 \mathrm{~mL}$ of TEPSA $(28 \mathrm{mmol})$ and $2.5 \mathrm{~mL}$ of tetramethylammonium hydroxide $1 \mathrm{M}(2.5 \mathrm{mmol})$ were added to the suspension. The reaction mixture was heated at $100^{\circ} \mathrm{C}$ for approximately $40 \mathrm{~h}$. ${ }_{25}$ After cooling to room temperature, the iron oxide nanoparticles were precipitated by an acetone/ether mixture $(50 / 50,300 \mathrm{~mL})$ and washed two times with acetone $(100 \mathrm{~mL})$. The suspension was finally dispersed in $100 \mathrm{~mL}$ of DI water and washed by ultrafiltration with ultrapure water. The iron concentration 0.156 $30 \mathrm{~mol}_{\mathrm{Fe}} \cdot \mathrm{L}^{-1}$ was measured accurately by $T_{1}$ relaxometry at $20 \mathrm{MHz}$ after mineralisation of the nanoparticles into ferric ions. The $\mathrm{COOH}$ moieties were titrated by conductimetry, yielding a molar ratio of $2.8 \mathrm{~mol} \%$ acidic functions compared to total iron content.

\section{Coating with poly(ether)monoamines by "grafting on"}

35 Jeffamine $^{\circledR}$ M-2005 and M-2070 were gifts from Huntsman, The Netherlands. Their compositions in EO and PO units and molar masses were checked by ${ }^{1} \mathrm{H}$ NMR, respectively $\mathrm{PEO}_{5}-s t-\mathrm{PPO}_{37}$ $\left(2400 \mathrm{~g} \cdot \mathrm{mol}^{-1}\right)$ for $\mathrm{M}-2005$ and $\mathrm{PEO}_{46}-\mathrm{st}-\mathrm{PPO}_{13}\left(2800 \mathrm{~g} \cdot \mathrm{mol}^{-1}\right)$ for $\mathrm{M}-2070$. The amines were titrated by perchloric acid in 1:2 (v/v) 40 chloroform / glacial acetic acid, yielding $97 \pm 2 \% \mathrm{NH}_{2}$ end-groups for the two poly(ether)amine batches. The two Jeffamine ${ }^{\circledR}$ polymers were grafted covalently onto TEPSA-coated iron oxide nanoparticles using carbodiimide (EDC) to activate the carboxylate groups of TEPSA. The conditions of the coupling 45 reaction were found optimal at $\mathrm{pH} 6$ with molar ratios $n_{\text {poly(ether)amine }} / n_{\mathrm{TEPSA}}=12.5$ and $n_{\mathrm{EDC}} / n_{\mathrm{TEPSA}}=10$. Briefly, $26 \mathrm{~mL}$ of phosphate buffer (pH 6) containing $0.52 \mathrm{~g}$ of Jeffamine ${ }^{\mathbb{R}} \mathrm{M}-2005$ $(220 \mu \mathrm{mol})$ or $0.62 \mathrm{~g}$ of Jeffamine ${ }^{\circledR} \mathrm{M}-2070(220 \mu \mathrm{mol})$ were added to $4 \mathrm{~mL}$ of $\mathrm{Fe}_{3} \mathrm{O}_{4}$-TEPSA nanoparticles suspension (624 $\left.{ }_{50} \mu \mathrm{mol}_{\mathrm{Fe}}, 17.5 \mu \mathrm{mol}_{\mathrm{COOH}}\right)$. To start the coupling reaction, $33.5 \mathrm{mg}$ of EDC $(175 \mu \mathrm{mol})$ were added. The mixture was stirred for $18 \mathrm{~h}$ below the LCST, i.e. at $4{ }^{\circ} \mathrm{C}$ for Jeffamine ${ }^{\circledR} \mathrm{M}-2005$ and at room temperature for M-2070. Finally, un-grafted chains were removed through dialysis for approximately $72 \mathrm{~h}$ with 10 bath changes. 55 Alternatively, the grafted suspension was diluted 20 times in DI water and then concentrated again by ultra-filtration under a nitrogen pressure across a regenerated cellulose membrane of pore size smaller than the USPIOs $\left(30000 \mathrm{~g} \cdot \mathrm{mol}^{-1}\right.$ molecular weight cut-off) until no trace of polymer was detected by FT-IR ${ }_{60}$ in the ultra-filtrate after freeze-drying.

\section{Instrumentation}

Dynamic light scattering (DLS) and phase analysis light scattering (PALS) were conducted on a Zetasizer NanoZS ZEN 3600 instrument (Malvern, UK) to measure the hydrodynamic ${ }_{65}$ diameters $\left(D_{\mathrm{h}}\right)$, polydispersity index $(\mathrm{PDI})$ and $\zeta$ potential of the nanoparticles. The measurements were performed in dilute suspensions in pure water, i.e. $16 \mathrm{~g} \cdot \mathrm{L}^{-1}$ for the polymer chains and around $1 \mathrm{mM}_{\mathrm{Fe}}\left(0.08 \mathrm{~g} \cdot \mathrm{L}^{-1}\right)$ for the USPIOs of different coatings. Reported $D_{\mathrm{h}}$ and PDI values were measured in triplicate from the $702^{\text {nd }}$ order cumulant fit of the correlograms obtained from scattered light intensity at $173^{\circ}$.

Transmission electron microscopy (TEM) images were recorded on a Hitachi $\mathrm{H} 7650$ microscope working at $80 \mathrm{kV}$ equipped with a GATAN Orius 11 Megapixel camera. Samples 75 were prepared by spraying a solution of the sample onto a copper grid (200 mesh coated with carbon) using a homemade spray tool. The images were analysed using automated particle counting of ImageJ software after thresholding and watershed filtering (http://rsbweb.nih.gov/ij/), enabling to build a histogram 80 of the diameters.

Nuclear magnetic relaxation dispersion (NMRD) profiles reporting the longitudinal relaxation rates of water protons $\left(R_{1}\right)$ over a magnetic field range from $0.24 \mathrm{mT}$ to $0.94 \mathrm{~T}$ were recorded on a Fast Field Cycling Relaxometer (Stelar, Mede, ${ }_{85}$ Italy). Additional longitudinal $\left(R_{1}\right)$ and transverse $\left(R_{2}\right)$ relaxation rates were measured at $0.47 \mathrm{~T}$ and $1.41 \mathrm{~T}$ on Minispec mq20 and mq60 relaxometers (Bruker, Karlsruhe, Germany). The saturation magnetisation, $M_{\mathrm{S}}$, and size of superparamagnetic crystals, $R_{\mathrm{NMR}}$, were determined by fitting these NMRD curves numerically with 90 the MINUIT minimisation program within the frame of the Outer Sphere model and a standard phenomenological approximation. ${ }^{19}$

Iron concentration was determined by longitudinal relaxation rate $\left(R_{1}\right)$ measurements at $0.47 \mathrm{~T}$ and $37^{\circ} \mathrm{C}$ after microwave digestion (MLS-1200 MEGA, Milestone) into ferric ions by a 95 mixture of nitric acid and hydrogen peroxide. ${ }^{20}$

Fourier transform infrared (FT-IR) transmission spectra were recorded in the range $450-4000 \mathrm{~cm}^{-1}$ through the samples dispersed in $\mathrm{KBr}$ pellets on a Spectrum $100 \mathrm{FT}$-spectrometer (Perkin Elmer, US).

100 Nuclear magnetic resonance (NMR) spectra were recorded on a Bruker Avance $500 \mathrm{MHz}$ spectrometer (Karlsruhe, Germany). Temperature was adjusted by an air flow or a liquid nitrogen flow controlled by a Bruker BVT 3200 unit. $90^{\circ}$ pulse and an acquisition delay of $1 \mathrm{~s}$ were used for ${ }^{1} \mathrm{H}$ spectral accumulations.

105 Thermogravimetric analyses (TGA) were conducted on a TA Q500 system (TA Instruments). Before analysis, the samples were first heated at $80^{\circ} \mathrm{C}$ during $24 \mathrm{~h}$ to eliminate free water. The mass loss of the pre-dried samples was monitored under nitrogen from room temperature to $120^{\circ} \mathrm{C}$ at a heating rate of $10^{\circ} \mathrm{C} / \mathrm{min}$. $110 \mathrm{After}$ an isotherm at $120^{\circ} \mathrm{C}$ under nitrogen during $10 \mathrm{~min}$ to remove the bound water, the samples were heated from $120^{\circ} \mathrm{C}$ to $600^{\circ} \mathrm{C}$ at a heating rate of $10^{\circ} \mathrm{C} / \mathrm{min}$ under air.

Low-field MR images of sample tubes were acquired on a Siemens Magnetom open magnet clinical scanner at $0.194 \mathrm{~T}$ $115(8.25 \mathrm{MHz}) . T_{1}$-weighted images were taken with a spin-echo 
sequence of $T R=100 \mathrm{~ms}, T E=2.8 \mathrm{~ms}, 70^{\circ}$ flip angle. $T_{2}{ }^{*}$-weighted images were taken with $T R=300 \mathrm{~ms}, T E=12 \mathrm{~ms}, 160 \times 160 \mathrm{~mm}^{2}$ field of view, $128 \times 128$ matrix, $7 \mathrm{~mm}$ slice thickness. The apparent transverse relaxation rates $R_{2}{ }^{*}=1 / T_{2}{ }^{*}$ at $8.25 \mathrm{MHz}$ were 5 measured for a series of six samples at increasing concentrations $\left(0.05,0.1,0.25,0.5,0.75\right.$, and $\left.1 \mathrm{mM}_{\mathrm{Fe}}\right)$ with a Carr Purcell Meiboom Gill (CPMG)-like sequence made of 16 echoes with 12 ms inter echo-time. For all MRI experiments, the samples in 2 $\mathrm{mL}$ vials were placed in a water jacket of temperature controlled 10 by a regulated circulating bath (Huber Polystat CC, Offenburg, Germany). Temperature was monitored inside the chamber in the magnet by a GaAs-based optical fibre thermometer compatible with radiofrequency magnetic fields (Opsens, Québec, Canada).

High-field MR images were taken on a Bruker PharmScan $1570 / 16$ for small animal imaging with a $7.05 \mathrm{~T}$ magnet $(300 \mathrm{MHz})$ with spin-echo sequences of $T R=1000 \mathrm{~ms}, T E=8.5 \mathrm{~ms}, 25.6 \times 25.6$ $\mathrm{mm}^{2}$ field of view, $256 \times 256$ matrix, and $2 \mathrm{~mm}$ slice thickness. Relaxivities at 7.05 T were measured on a Bruker Avance 300.

\section{Results and Discussion}

\section{${ }_{20}$ Solution properties of the poly(ether)amine chains}

The LCST values of Jeffamine ${ }^{\circledR}$ M-2005 and M-2070 were determined by two different methods, DLS intensity and NMR spectroscopy. The cloud points of the two polymer solutions at 16 $\mathrm{g} \cdot \mathrm{L}^{-1}$ in $\mathrm{H}_{2} \mathrm{O}$ were measured by following the backscattered 25 intensity at $173^{\circ}$ : the inflection points were respectively near $22 \pm 2^{\circ} \mathrm{C}$ and $52 \pm 2^{\circ} \mathrm{C}$ for Jeffamine ${ }^{\circledR} \mathrm{M}-2005$ and M-2070 (Fig. 1). In the meanwhile, the liquid state proton NMR signal of the polymer backbone fell down above the LCST, because of a globular state analogous to a solid state. ${ }^{21}$ The ${ }^{1} \mathrm{H}$ spectra of the 30 poly(ether)amine solutions at $30 \mathrm{~g} \cdot \mathrm{L}^{-1}$ in $\mathrm{D}_{2} \mathrm{O}$ were recorded at increasing temperatures (Fig. S1 in Supporting Information). Fig. 1 shows the steep signal decrease when temperature exceeded $25^{\circ} \mathrm{C}$ for M-2005: the curve of NMR signal appeared almost symmetrical to the plot of DLS intensity. In the case of M-2070, 35 the drop of NMR signal was only $10 \%$ above $55^{\circ} \mathrm{C}$. However a weak inflection symmetrical to the DLS curve can still be identified as a sign of the LCST. But it is only above $80^{\circ} \mathrm{C}$ that the NMR signal started to decrease significantly. We interpret this apparent discrepancy as due to the sensitivity of DLS to the 40 onset of the transition when the very first clusters of polymer globules started to aggregate (and then sediment, causing a slight decrease of the DLS intensity, as seen at $35^{\circ} \mathrm{C}$ for M-2005 and $65^{\circ} \mathrm{C}$ for $\left.\mathrm{M}-2070\right)$. In contrast, the ${ }^{1} \mathrm{H}$ NMR intensity probes the local environment of the chains that became fully dehydrated at a

45 high temperature than the LCST. Nevertheless, the inflection point of the curves provides a good determination of the LCST for both polymers with both techniques.

\section{Characterization of the inorganic cores}

TEM images of USPIOs grafted with Jeffamine ${ }^{\circledR}$ M-2005 were 50 used to determine the size distribution of the magnetic cores, since they appeared well separated from each-other by the polymer shell. Diameters obtained by TEM follow a log-normal distribution (Fig. 2) with a median diameter $d_{0}=8 \mathrm{~nm}$ and a standard width $\sigma=0.4$. The number-average diameter is $\langle d\rangle=$ ${ }_{55} 8.6 \mathrm{~nm}$ and the volume-average $\left\langle d^{4}\right\rangle /\left\langle d^{3}\right\rangle=13.9 \mathrm{~nm}$, giving a polydispersity index (ratio of the two values) equal to 1.6. Such broadness is typical for the synthesis by alkaline coprecipitation in polyol

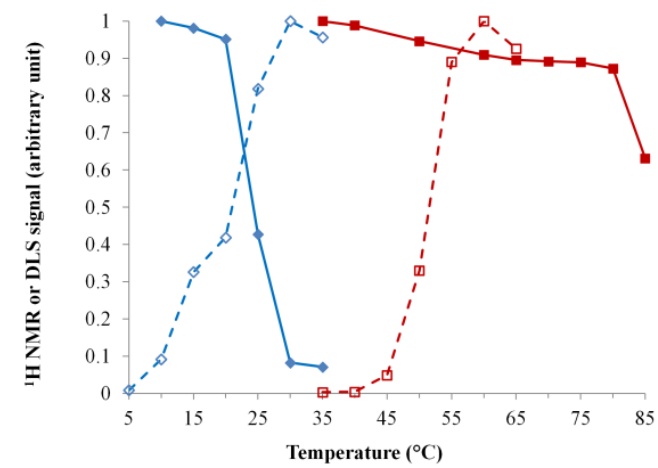

60 Fig. 1 Normalised area under the ${ }^{1} \mathrm{H}$ NMR spectrum (filled markers, solid lines) and derived count-rate in DLS (empty markers, dotted lines) vs. temperature for Jeffamine ${ }^{\circledR} \mathrm{M}-2005$ (blue) and M-2070 (red) at 16 $\mathrm{mg} \cdot \mathrm{mL}^{-1}$ in $\mathrm{H}_{2} \mathrm{O}$ for DLS and $30 \mathrm{mg} \cdot \mathrm{mL}^{-1}$ in $\mathrm{D}_{2} \mathrm{O}$ for NMR. The LCST is determined at the inflections points of both curves, $22 \pm 2{ }^{\circ} \mathrm{C}$ for M-2005, ${ }_{65} 52 \pm 2^{\circ} \mathrm{C}$ for $\mathrm{M}-2070$ (in that case a second transition above $80^{\circ} \mathrm{C}$ is visible by NMR, corresponding to full dehydration of the chains).

a)
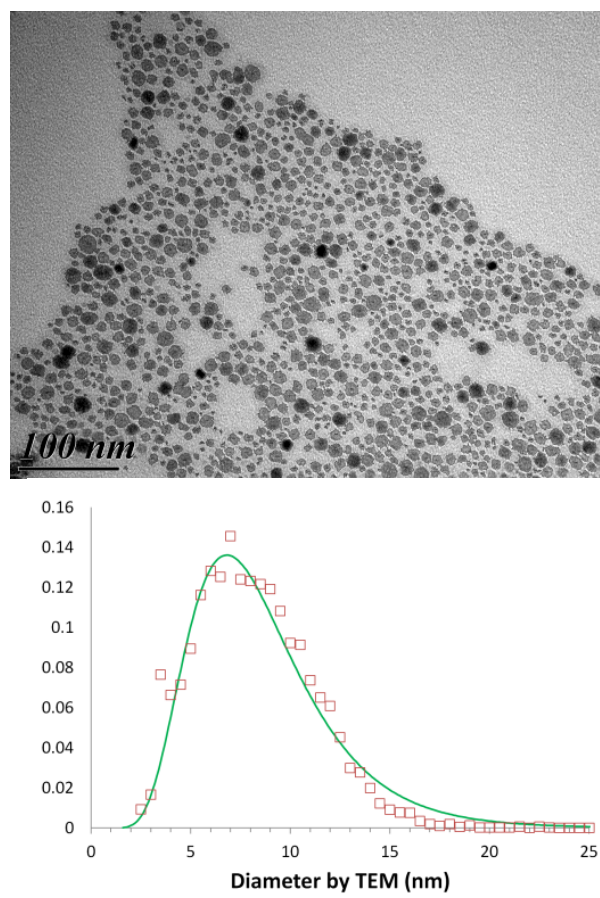

b)

Fig. 2 a) TEM image of Jeffamine ${ }^{\circledR}$ M-2005 coated-USPIOs (scale bar $70100 \mathrm{~nm}$ ) and $\mathrm{b}$ ) histogram of TEM diameters deduced by automatic particle counting (red square) on five images with a total number of 7950 nanoparticles, and fitted by a log-normal law (green line) of parameters $d_{0}=8 \mathrm{~nm}$ and $\sigma=0.4$.

\section{Characterisation of the organic coating of the nanoparticles}

75 The organic shell composed of a first TEPSA organosilane layer, then the polymer, was analysed by FT-IR spectroscopy (Fig. S2 and S4), TGA (Table 1, Fig. S3), DLS and zetametry (Fig. 3).

At first, the FT-IR spectrum of USPIOs synthesised by alkaline coprecipitation of $\mathrm{FeCl}_{2}$ and $\mathrm{FeCl}_{3}$ in DEG medium (Fig. ${ }_{80} \mathrm{~S} 2 \mathrm{a}$ ) contains bands at 591 and $635 \mathrm{~cm}^{-1}$ originating from $\mathrm{Fe}-\mathrm{O}$ stretching of the $\mathrm{Fe}_{3} \mathrm{O}_{4}$ cores. The narrow peak at $1384 \mathrm{~cm}^{-1}$ is ascribed to nitrate ions physisorbed on iron oxide surface. The 
spectrum also contains a band at $1630 \mathrm{~cm}^{-1}$ due to water physisorbed on iron oxide surface and a broad band around 3400 $\mathrm{cm}^{-1}$ due to surface hydroxyl groups $(\mathrm{Fe}-\mathrm{OH})$.

The FT-IR spectrum of USPIOs grafted with TEPSA (Fig. ${ }_{5} \mathrm{~S} 2 \mathrm{~b}$ ) shows a band at $1119 \mathrm{~cm}^{-1}$ characteristic of Si-O bonds. The band at $2925 \mathrm{~cm}^{-1}$ originates from $\mathrm{C}-\mathrm{H}$ stretching of $\mathrm{CH}_{2}$ groups. The bands at 1711, 1560 and $1404 \mathrm{~cm}^{-1}$ are assigned to carboxylates. As a result, the presence of a TEPSA layer on the iron oxide surface was confirmed by infrared spectroscopy.

10 Table 1 Weight compositions of hybrid USPIOs measured by TGA

\begin{tabular}{cccccc} 
Sample (coating) & $\begin{array}{c}\text { Bound } \\
\text { water } \\
\text { (wt. \%) }\end{array}$ & $\begin{array}{c}\text { Inorganics } \\
\text { =Iron oxide } \\
\text { (wt. \%) }\end{array}$ & $\begin{array}{c}\text { Total } \\
\text { organics } \\
\text { (wt. \%) }\end{array}$ & $\begin{array}{c}\text { TEPSA } \\
\text { (wt. \%) }\end{array}$ & $\begin{array}{c}\text { Polymer } \\
\text { (wt. \%) }\end{array}$ \\
\hline TEPSA coated & $2.7^{a}$ & $87.5^{a}$ & $12.5^{a}$ & $12.5^{a}$ & 0 \\
& & $100^{b}$ & $14.3^{b}$ & $14.3^{b}$ & \\
M-2005 coated & $1.4^{a}$ & $60.1^{a}$ & $39.9^{a}$ & $8.6^{a}$ & $31.3^{a}$ \\
& & $100^{b}$ & $66.4^{b}$ & $14.3^{b}$ & $52.1^{b}$ \\
M-2070 coated & $1.6^{a}$ & $77.8^{a}$ & $22.2^{a}$ & $11.1^{a}$ & $11.1^{a}$ \\
& & $100^{b}$ & $28.5^{b}$ & $14.3^{b}$ & $14.2^{b}$
\end{tabular}

${ }^{a}$ relatively to dry matter at $120^{\circ} \mathrm{C} ;{ }^{b}$ ratio to burnt matter at $600^{\circ} \mathrm{C}$.

To quantify this layer, an organic-to-inorganic ratio of $14.3 \%$ was determined from the weight loss on the TGA curve of the TEPSA-coated USPIOs (Fig. S3). We deduced the number $n_{\text {TEPSA }}$ 15 of organosilane molecules grafted to the USPIO nanoparticle by:

$$
\frac{\text { organic wt. } \%}{\text { inorganic wt. } \%}=\frac{n_{\text {TEPSA }} \times M_{\mathrm{w}}^{\text {TEPSA }}}{M_{\mathrm{w}}^{\mathrm{USPIO}}}
$$

with the molar mass of particle $M_{\mathrm{w}}^{\text {USPIO }}$ estimated geometrically:

$$
M_{\mathrm{w}}^{\mathrm{USPIO}}=\rho \times N_{\mathrm{A}} \times \frac{4}{3} \pi r_{\mathrm{USPIO}}^{3}
$$

where $N_{\mathrm{A}}$ is the Avogadro number and $\rho$ the mass density of ${ }_{20} \mathrm{Fe}_{3} \mathrm{O}_{4}, \rho=5180 \mathrm{~kg} \cdot \mathrm{m}^{-3}$. Using $r_{\text {USPIO }}=5.5 \mathrm{~nm}$ as determined later by relaxometry $\left(R_{\mathrm{NMR}}\right)$, one finds $M_{\mathrm{w}}^{\mathrm{USPIO}} \approx 2 \times 10^{6} \mathrm{~g} \cdot \mathrm{mol}^{-1}$. Since $M_{\mathrm{w}}{ }^{\mathrm{TEPSA}}=304.4 \mathrm{~g} \cdot \mathrm{mol}^{-1}$, the number of molecules in the coating is $n_{\mathrm{TEPSA}} \approx 1000$ molecules per nanoparticle, covering an area $4 \pi \times\left(r_{\text {USPIO }}\right)^{2} \approx 380 \mathrm{~nm}^{2}$. From these values, a surface density of 2.6 25 TEPSA molecules per $\mathrm{nm}^{2}$ is estimated, in accordance with values reported in the literature for silane monolayers on ferrite nanoparticles. $^{7}$

For USPIO nanoparticles firstly coated with TEPSA then coupled to Jeffamine ${ }^{\circledR}$ chains, the organic content measured by 30 TGA is the sum of the two components:

$$
\frac{\text { organic wt. } \%}{\text { inorganic wt. } \%}=\frac{n_{\text {TEPSA }} \times M_{\mathrm{w}}^{\mathrm{TEPSA}}}{M_{\mathrm{w}}^{\mathrm{USPIO}}}+\frac{n_{\text {polymer }} \times M_{\mathrm{w}}^{\text {polymer }}}{M_{\mathrm{w}}^{\mathrm{USPIO}}}
$$

The grafting density of the silane being a priori not affected by the coupling reaction of the polymer, the weight ratio of TEPSA relatively to $\mathrm{Fe}_{3} \mathrm{O}_{4}$ can be considered constant (14.3 wt.\%) for all 35 samples. With this hypothesis of constant TEPSA-to-iron-oxide weight fraction, the first term of this sum can be subtracted from the left hand of Eq. (4) (total organic-to-inorganic content), yielding the fraction of polymer relatively to inorganic weight (Table 1). Finally, this polymer-to-inorganic ratio enables to 40 estimate the number of chains per USPIO: $n_{\text {polymer }} \approx 430$ chains per
USPIO for Jeffamine ${ }^{\circledR} \mathrm{M}-2005\left(M_{\mathrm{w}}{ }^{\text {polymer }}=2400 \mathrm{~g} \cdot \mathrm{mol}^{-1}\right)$, and $n_{\text {polymer }} \approx 100$ chains for M-2070 $\left(M_{\mathrm{w}}^{\text {polymer }}=2800 \mathrm{~g} \cdot \mathrm{mol}^{-1}\right)$. The yields of the chain coupling were thus respectively $43 \%$ and $10 \%$.

The grafting of Jeffamine ${ }^{\circledR}$ onto the surface of USPIOs was 45 also studied by FT-IR spectroscopy. Unfortunately, the amide bond formation between the carboxylic acid of TEPSA and the amino group of Jeffamine ${ }^{\circledR}$ could not be detected directly on the raw spectra, since the $\mathrm{C}=\mathrm{O}$ vibration was expected to overlap the wide band between 1550 and $1700 \mathrm{~cm}^{-1}$ of USPIOs coated by 50 TEPSA only (Fig. S2b). To highlight the presence of amide bands, the two FT-IR spectra of USPIOs coated with TEPSA respectively before and after the grafting of Jeffamine ${ }^{\circledR}$ were first normalised relatively to iron oxide by setting the same absorption of the $\mathrm{Fe}-\mathrm{O}$ bond in the $450-600 \mathrm{~cm}^{-1}$ range. Then they were 55 subtracted and plotted in the $1000-2000 \mathrm{~cm}^{-1}$ wave number range (Fig. S4a for M-2005 and Fig. S5a for M-2070). The resulting spectrum shows three bands ascribed to carbonyl groups (red circle), two in the $1650-1690 \mathrm{~cm}^{-1}$ range for amide carbonyle groups (amide band $\mathrm{I}$ for $\mathrm{C}=\mathrm{O}$, amide band $\mathrm{II}$ for $\mathrm{N}-\mathrm{H}$ ) and one ${ }_{60}$ characteristic of the remaining carboxylic acids $\left(1730 \mathrm{~cm}^{-1}\right)$. The other bands at lower wave numbers (one near $1455 \mathrm{~cm}^{-1}$, four bands between 1400 and $1250 \mathrm{~cm}^{-1}$ and one band near $1100 \mathrm{~cm}^{-1}$, blue circles) were typical of poly(ether)amines, as compared to the spectra of the pure polymers (respectively Fig. S4b and S5b). ${ }_{65}$ The coupling of the amino-terminated polymers with the carboxylic acids of the organosilane coating on the iron oxide surface was thus proven undoubtedly.

\section{Colloidal behaviour of the grafted nanoparticles}

70 The colloidal state of the suspensions was probed by dynamic and phase analysis light scattering techniques. Fig. 3 shows the $\zeta$ potential of the raw, the TEPSA-coated and Jeffamine ${ }^{\circledR}$-coated USPIOs followed by PALS vs. $\mathrm{pH}$ to locate their point of zero charge (PZC). The hydrodynamic diameters were taken as the 75 intensity-average diameters measured by DLS. Dispersed in dilute $\mathrm{HNO}_{3}$ medium, the bare USPIOs exhibit a $D_{\mathrm{h}}=14.3 \pm 0.2 \mathrm{~nm}$ (PDI=0.13). After grafting of TEPSA, $D_{\mathrm{h}}$ became equal to $18.0 \pm 0.1 \mathrm{~nm}(\mathrm{PDI}=0.13)$. Values measured again after 1 month did not vary significantly. In addition to this increase of $D_{\mathrm{h}}$ by 80 about $4 \mathrm{~nm}$ between coated and un-coated USPIOs, the organic and highly hydrated shell was also attested by the plot of the $\zeta$ potential as a function of $\mathrm{pH}$ (Fig. 3). The $\mathrm{PZC}$ was initially at $\mathrm{pH}$ 5.8 , a typical value for iron oxide. After grafting with TEPSA, the PZC was shifted to $\mathrm{pH} \approx 3$. The USPIO nanoparticles became 85 stable on a much wider range of $\mathrm{pH}$, i.e. for $\mathrm{pH}$ higher than 4.5. Deprotonated above this $\mathrm{pH}$, the carboxylic acid functions of TEPSA provide strong enough electrostatic repulsion to prevent the aggregation of the USPIOs, as seen from a strongly negative $\zeta$ potential $(-30 \mathrm{mV}$ at $\mathrm{pH} 4.5$, and $-40 \mathrm{mV}$ above $\mathrm{pH} 6$ with fully 90 deprotonated carboxylates). 


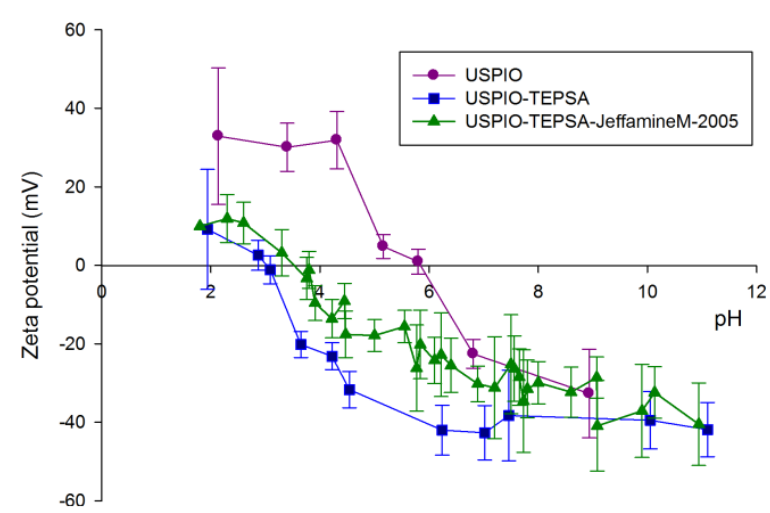

Fig. 3 Evolution of $\zeta$ potential of the raw iron oxide nanoparticles after coprecipitation (purple circles), after coating with TEPSA (blue squares) and after grafting of Jeffamine ${ }^{\circledR} \mathrm{M}-2005$ (green triangles) $v s . \mathrm{pH}$. The

5 error bars represent the experimental uncertainty of the PALS method for each data point, which increases towards lower or higher $\mathrm{pH}$ due to the increased salinity forcing to lower the voltage to $50 \mathrm{~V}$ instead of $150 \mathrm{~V}$.

The curve of $\zeta$ potential vs. $\mathrm{pH}$ for the polymer-coated nanocrystals was slightly shifted towards higher $\mathrm{pH}$ values 10 compared to the silane-coated ones. This phenomenon is ascribed to partial hydrodynamic screening of the negative charges of the remaining carboxylates groups by the polymer chains. Negative $\zeta$ potential values with a PZC in the range $\mathrm{pH}=4.5-5$ was already reported in the literature for poly(ether)amine coated-USPIOs and 15 was explained by residual surface charges arising from the organosilane layer, in that case deprotonated hydroxyl groups. ${ }^{4}$

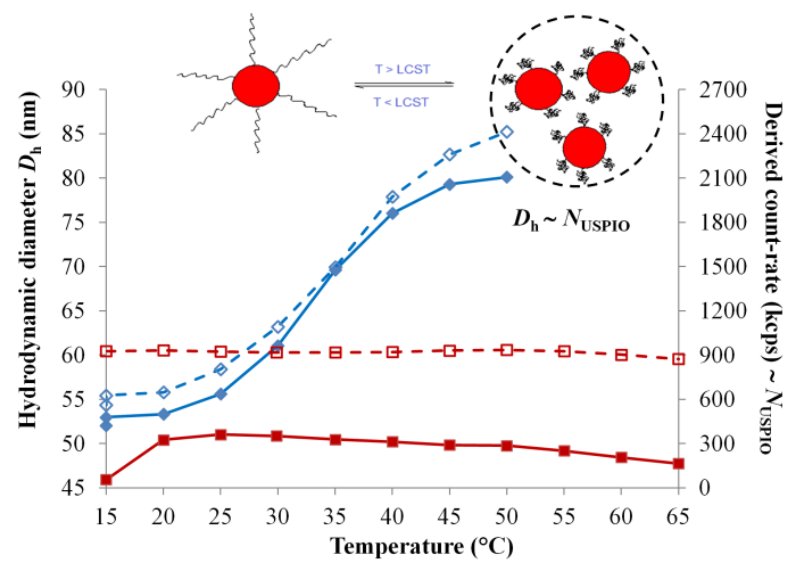

Fig. 4 Intensity-average hydrodynamic diameter $D_{\mathrm{h}}(\mathrm{nm}$, filled markers, solid lines) and derived count-rate in DLS (empty markers, dotted lines) $20 \quad v s$. temperature for USPIOs grafted with Jeffamine ${ }^{\circledR} \mathrm{M}-2005$ (blue) and $\mathrm{M}-2070$ (red). The measurements were performed at $1 \mathrm{mM}_{\mathrm{Fe}}$ in water. The grafting of M-2005 chains formed USPIOs clusters of size and aggregation number both increasing with temperature, whereas TEPSAcoated USPIOs remained individually dispersed over the whole $T$-range.

25 The hydrodynamic size $\left(D_{\mathrm{h}}, \mathrm{PDI}\right)$ and the scattered intensity of the USPIOs grafted with Jeffamine ${ }^{\circledR}$ chains were followed by DLS as a function of temperature at $\mathrm{pH} 6$ in the range $15-65^{\circ} \mathrm{C}$ (Fig. 4). At $15^{\circ} \mathrm{C}$, the hydrodynamic sizes were respectively $D_{\mathrm{h}}=52 \mathrm{~nm}(\mathrm{PDI}=0.07)$ for the USPIOs grafted with Jeffamine ${ }^{\circledR}$ $30 \mathrm{M}-2005$ and $D_{\mathrm{h}}=46 \mathrm{~nm}(\mathrm{PDI}=0.26)$ for those grafted with Jeffamine ${ }^{\circledR}$ M-2070. The intensity scattered by the particles and their sizes (calculated at each temperature with the appropriate value of water viscosity) appeared constant for USPIOs grafted with the most hydrophilic chains, Jeffamine ${ }^{\circledR} \mathrm{M}-2070$ up to $65^{\circ} \mathrm{C}$, 35 in agreement with the weaker grafting density (yield of the chain coupling $=10 \%$ ) and/or an incomplete dehydration of the polymer chains below $80^{\circ} \mathrm{C}$. On the contrary, the colloidal state highly depends on temperature for USPIOs grafted with Jeffamine ${ }^{\circledR}$ M-2005 (LCST of the chains in solution at $22 \pm 2^{\circ} \mathrm{C}$ ).

${ }_{40}$ Both $D_{\mathrm{h}}$ and the scattered intensity exhibited an increase with a sigmoid shape in the $15-50{ }^{\circ} \mathrm{C}$ range. Apparently, the two sigmoid curves can be superposed on a double-axis plot (Fig. 4), meaning a proportionality factor between them. The clusters of USPIOs were thus rather tenuous (low $\Phi_{\text {intra }}$ ), since the number of ${ }_{45}$ USPIOs per aggregate (proportional to the scattered intensity) would have varied rather with the power 3 of $D_{\mathrm{h}}$ for dense clusters, whereas here it varied linearly with the cluster size. This information is useful to interpret the relaxometric properties later on.

50

\section{Relaxometric properties of LCST polymer-coated USPIOs}

Relaxivities of the USPIO nanoparticles grafted with polymers were studied as a function of temperature for both Jeffamine ${ }^{\circledR}$ batches. But in view of its lower LCST, the results are 55 emphasised for M-2005, the relaxometric data for M-2070 being given as controls in supporting information (Fig. S6 and S7). While $r_{1}$ was obtained as a function of frequency using Fast Field Cycling relaxometry, $r_{2}$ was measured at discrete frequencies relevant for clinical MRI scanners: 8.25, 20, 60 and $300 \mathrm{MHz}$. 


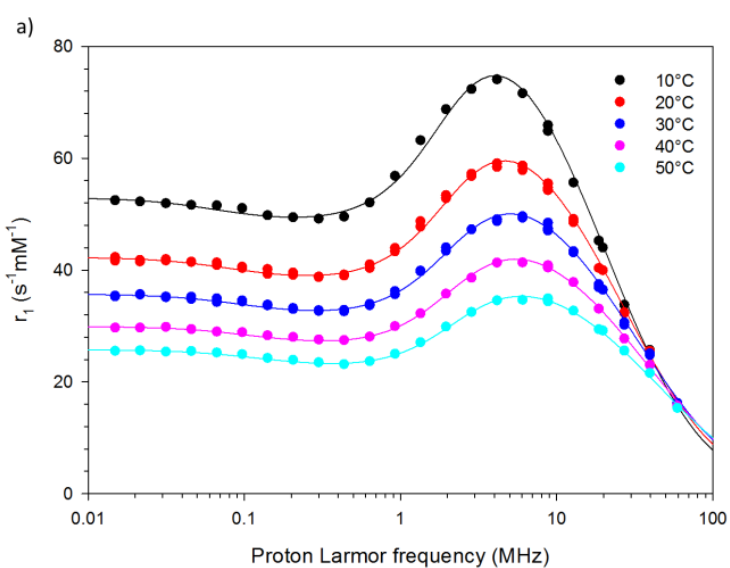

b)

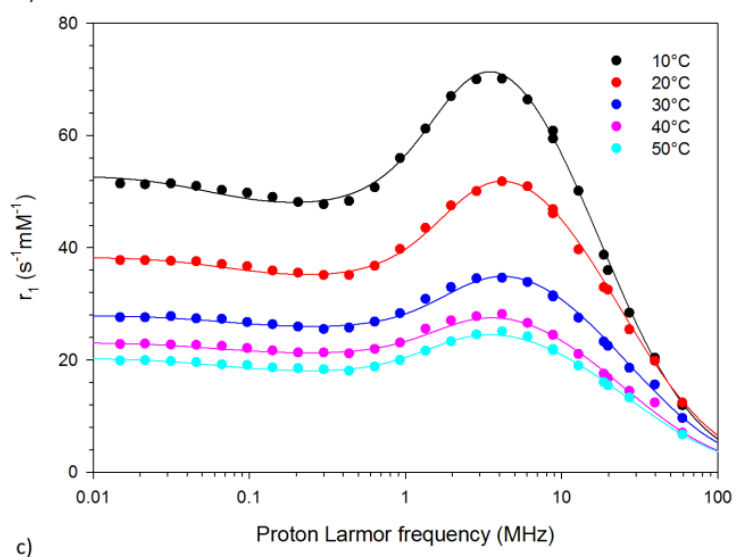

c)

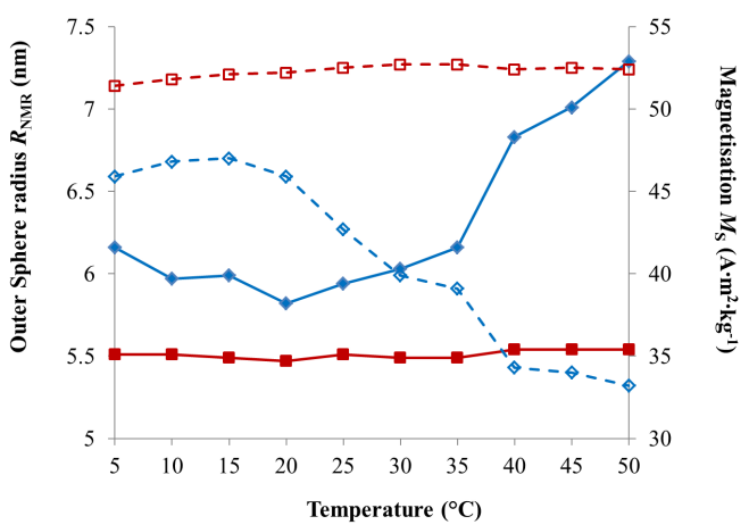

Fig. 5 NMRD profiles of the longitudinal relaxivity $v s$. Larmor frequency for a) TEPSA-coated USPIOs, and b) USPIOs grafted with Jeffamine ${ }^{\circledR}$ M-2005; c) relaxometric radius $R_{\mathrm{NMR}}$ (nm, filled markers, solid lines) and 5 saturation magnetisation $M_{\mathrm{S}}$ (empty markers, dotted lines) $v s$. temperature for USPIOs coated by Jeffamine ${ }^{\mathbb{R}}$ M-2005 (blue) and TEPSA only (red).

NMRD profiles, i.e. the curves of the longitudinal relaxivity $r_{1}$ $v s$. frequency $v$ were recorded before (Fig. 5a) and after (Fig. 5b) grafting of Jeffamine ${ }^{\circledR}$ M-2005 onto the TEPSA layer around the ${ }_{10}$ USPIOs at varying temperatures. These curves exhibited a profile typical for USPIOs, with a plateau at low frequency ascribed to the Néel fluctuations of the magnetic moments, a maximum at an intermediate frequency due to their orientation by the magnetic field (Curie mechanism) and a dropping down towards high 15 frequencies usually interpreted as the absence of a "secular term" in the equation describing $T_{1}$ relaxation. ${ }^{19}$ The whole curve $r_{1}(v)$ was shifted to lower values when temperature increased. The predominant cause is the decrease of viscosity with temperature, accelerating the diffusion of water molecules around the USPIO 20 and shortening the interaction between nuclear spins of protons and electronic spins of the USPIO. But the decrease became more abrupt when Jeffamine ${ }^{\circledR}$ M-2005 was grafted on top of the TEPSA layer, especially near the LCST between $20^{\circ} \mathrm{C}$ and $30^{\circ} \mathrm{C}$.

A heuristic method to simplify the relaxation equations enables ${ }_{25}$ fitting such NMRD profiles $r_{1}(v)$ : the resulting parameters are the relaxometric radius $\left(R_{\mathrm{NMR}}\right)$, the saturation magnetisation $\left(M_{\mathrm{S}}\right)$ of the Outer Sphere model equivalent to the iron oxide nanoparticles including their non-magnetic shell impermeable to water protons, and the diffusion constant of water molecules $D .{ }^{19}$ Usually one 30 takes $D=3 \times 10^{-9} \mathrm{~m}^{2} \cdot \mathrm{s}^{-1}$ in the model, which is the diffusion constant of water at $37^{\circ} \mathrm{C}$. For the other temperatures studied here, $D$ was set at values reported in literature. ${ }^{24}$ Fig. $4 \mathrm{c}$ shows the plots of $R_{\mathrm{NMR}}$ and $M_{\mathrm{S}}$ deduced from the fits as a function of temperature. For USPIOs coated with a TEPSA layer only, the 35 outer sphere radius and the magnetisation were found constant from $5^{\circ} \mathrm{C}$ to $50^{\circ} \mathrm{C}\left(R_{\mathrm{NMR}} \approx 5.5 \mathrm{~nm}\right.$ and $\left.M_{\mathrm{S}} \approx 52 \mathrm{~A} \cdot \mathrm{m}^{2} \cdot \mathrm{kg}^{-1}\right)$, thereby confirming that the continuous lowering of the whole NMRD curve of the control TEPSA-coated USPIOs when temperature increases on Fig. 4a can be explained by the tabulated change of ${ }_{40} D$ with temperature, i.e. the viscosity effect.

On the contrary, the fitted parameters for USPIOs grafted with Jeffamine ${ }^{\circledR} \mathrm{M}-2005$ were found nearly constant only from $5^{\circ} \mathrm{C}$ to $20^{\circ} \mathrm{C}\left(R_{\mathrm{NMR}} \approx 6 \mathrm{~nm}\right.$ and $\left.M_{\mathrm{S}} \approx 46 \mathrm{~A} \cdot \mathrm{m}^{2} \cdot \mathrm{kg}^{-1}\right)$, but then varied in opposite directions once the LCST of the chains was reached.

${ }_{45}$ Compared to nanoparticles coated by TEPSA only, those grafted with Jeffamine ${ }^{\circledR}$ M-2005 showed already below the LCST an increase of relaxometric radius by $\sim 0.5 \mathrm{~nm}$ (as apparent from the slight shift of the curve towards lower $v$ ) and a concomitant decrease of saturation magnetisation. These two observations can 50 be ascribed to a non-magnetic layer wrapping the oxide cores, also impermeable to water protons, as sketched on Scheme 1. When passing the LCST of Jeffamine ${ }^{\circledR}$ M-2005, these two phenomena were amplified. The formation of a hydrophobic coating surrounding the USPIOs increases the minimal approach 55 distance between the iron oxide surface and the water protons by $\sim 1.8 \mathrm{~nm}$, a quite reasonable size for polymer chains around 2400 $\mathrm{g} \cdot \mathrm{mol}^{-1}$ in the collapsed (bad solvent) or globular state. 

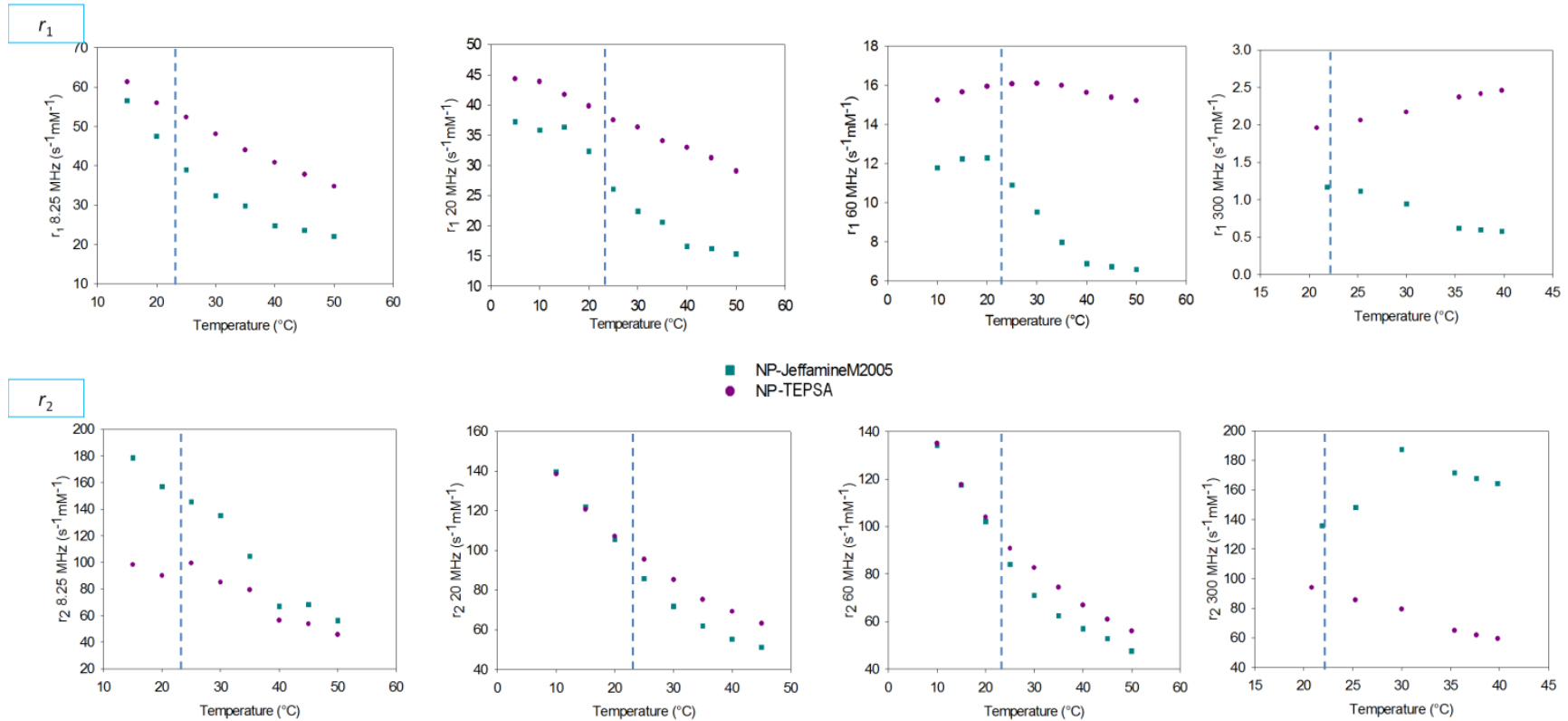

Fig. 6 Longitudial $\left(r_{1}\right.$, top) and transverse $\left(r_{2}\right.$, bottom) relaxivities at clinically relevant frequencies (from left to right: $8.25,20,60$, and $300 \mathrm{MHz}$ ) for TEPSA-coated USPIOs (purple markers) and USPIOs grafted with Jeffamine ${ }^{\circledR}$ M-2005 (green markers) as a function of temperature from 10 to $50^{\circ} \mathrm{C}$. The vertical dotted lines show the position of the LCST, concomitant with an inflection of the curve of $r_{2} v s . T$.

5 Relaxivities $r_{1}$ and $r_{2}$ at frequencies of clinical MRI scanners $(8.25,20,60 \mathrm{MHz})$ and at the highest field operated on humans (300 MHz) were plotted as a function of temperature (Fig. 6) for the USPIOs coated by TEPSA only and by Jeffamine ${ }^{\circledR}$ M-2005. Concerning longitudinal relaxation at these four frequencies, $r_{1}$ 10 was lower for the polymer-coated USPIOs than for the ones coated by just a silane layer, in accordance with the presence of a barrier impermeable to water protons. For the TEPSA-coated USPIOs, the variation of $r_{1}$ with temperature was not the same for all the frequencies: being a decreasing function at 8.25 and 20 $15 \mathrm{MHz}$, it was nearly flat at $60 \mathrm{MHz}$ and became even a slightly increasing function at $300 \mathrm{MHz}$. Such a complex variation of $r_{1}$ of USPIOs, either increasing or decreasing with temperature, was described in a recent report, and ascribed to their variation of magnetic anisotropy depending upon their size and synthesis 20 route. $^{23}$ In contrast, $r_{2}$ was always a decreasing function of temperature at all frequencies for the TEPSA-coated USPIOs, in accordance with the Outer Sphere model predicting a $r_{2}$ value as eqn (1) inversely proportional to the diffusion constant of water molecules, which increases with temperature. ${ }^{\mathbf{1 2}}$ For the USPIOs 25 grafted with Jeffamine ${ }^{\circledR} \mathrm{M}-2005$, the plot of longitudinal relaxativity $v s$. temperature showed a sigmoid shape with an inflection point near the LCST of the chains at all frequencies (this effect was even more pronounced when dividing $r_{1}$ with by its value for the TEPSA-only control as on Fig. S8).

30 For the transverse relaxation of protons, $r_{2}$, the comparison between data of USPIOs coated by the polymer chains and of the uncoated ones led to a discrepancy between $r_{2}$ values obtained at 20 and $60 \mathrm{MHz}$ on the one hand and at 8.25 and $300 \mathrm{MHz}$ on the other hand: in the first case, the transverse relaxivity was 35 identical for coated and uncoated USPIOs below the LCST, while above the LCST, $r_{2}$ decreased more rapidly than expected just by the temperature effect on water diffusivity (with TEPSA only). It should be noted that the direct temperature effect on the magnetic properties of the iron oxide can be ruled out to explain this 40 decrease of $r_{2}$ : the Langevin function indeed decreases slightly with temperature, but once temperature is expressed in Kelvin, this effect appears negligible compared to the effect of temperature on the solvent diffusivity, which is much more pronounced.

45 The steeper decrease of $r_{2}$ in the case of USPIOs coated by the polymer chains compared to simply a TEPSA silane layer can be interpreted by a fully hydrated polymer shell below the LCST, totally permeable to water, so that protons can reach the iron oxide surface where the field lines of the magnetic moment are 50 strong (Scheme 1) just as in the uncoated case. Above the LCST, the polymer shell collapsed, leading to a lower $r_{2}$ due the decrease of magnetisation caused by the dilution of iron oxide by the non-magnetic layer (i.e. the same explanation as for the $r_{1}$ decrease). On the contrary, transverse relaxivities measured at 558.25 and $300 \mathrm{MHz}$ were higher for the polymer-coated USPIOs than for uncoated ones at all temperatures. At $8.25 \mathrm{MHz}$, a plausible explanation is that the $T_{2}$-measuring sequences used on a MRI scanner did not have the same refocusing pulses as the CPMG spin echo method of a relaxometer, and thus measured the ${ }_{60} T_{2}$ * relaxation time rather than the pure $T_{2}$. At low temperature, the USPIOs coated by a swollen hydrophilic polymer shell exhibited the same $r_{2}$ as the uncoated ones (as measured at 20 and $60 \mathrm{MHz}$ on relaxometers), but the magnetic field homogeneity was perturbed, as attested by $r_{2}{ }^{*}$ values measured on the 8.25 ${ }_{65} \mathrm{MHz}$ MRI scanner much higher than $r_{2}$. Since the $r_{2}$ values at 300 $\mathrm{MHz}$ were measured on a NMR spectrometer and not a MRI scanner, the explanation must be different. In that case the much larger transverse relaxivity for the polymer-coated USPIOs compared to uncoated ones was ascribed to clustering by strong 70 magnetic dipolar interactions, which causes a well-known 
increase of $r_{2}$. The electro-steric repulsion brought by Jeffamine ${ }^{\circledR}$ chains thus appeared to be less efficient to prevent USPIOs aggregation under a very high magnetic field than the electrostatic repulsion between highly negatively charged 5 carboxylated silane layers.

The behaviour when temperature was increased also appeared to be different at low-field and at high-field. The intensity of magnetic dipolar interactions between clustered USPIOs varies indeed with the magnetic field value. At $8.25 \mathrm{MHz}$, the magnetic 10 field was weak $\left(B_{0}=0.194 \mathrm{~T}\right)$ and the magnetic moments were far from being saturated. In that case the collapse of chains above the LCST led to finite USPIOs clusters that must be around the same size as those measured by DLS in a zero magnetic field, $D_{\mathrm{h}} \approx 80$ $\mathrm{nm}$ at $50^{\circ} \mathrm{C}$. These clusters are also not very dense, as on the 15 sketch deduced from the limited scattered intensity plotted on Fig. 4. The internal volume fraction of iron oxide is indeed one of the three control parameters determining the transverse relaxivity in addition to the size $\left(R_{\mathrm{NMR}}\right.$ or $\left.D_{\mathrm{h}}\right)$ and magnetisation. ${ }^{12}$ For such tenuous aggregates above the LCST, $\Phi_{\text {intra }}$ must be much lower 20 than for individually dispersed USPIOs. More precisely, $\Phi_{\text {intra }}$ varies like the number of USPIOs divided by the total volume, $\Phi_{\text {intra }} \sim N_{\mathrm{USPIO}} / D_{\mathrm{h}}{ }^{3}$. The magnetisation $M_{\mathrm{S}}$ of the Outer Sphere equivalent to the aggregate being also proportional to $\Phi_{\text {intra }}$ (and to the specific magnetisation of the magnetic cores), the 25 transverse relaxivity estimated by Eq. (1) varies as $r_{2} \sim \Phi_{\text {intra }} \cdot D_{\mathrm{h}}{ }^{2} / D$ or equivalently $r_{2} \sim N_{\mathrm{USPIO}} /\left(D_{\mathrm{h}} \cdot D\right)$. When temperature increased, both the aggregation number and the hydrodynamic diameter increased, but remained proportional to each other (Fig. 4). As a result, the clustering effect was too weak to enhance $r_{2}$, and the
30 dominant effect was the increase of water diffusivity $(D)$ with temperature as for individual TEPSA-coated USPIOs, explaining the decrease of $r_{2}$ and $r_{2}^{*}$ at $8.25 \mathrm{MHz}$ (and up to $60 \mathrm{MHz}$ ). On the contrary, at $300 \mathrm{MHz}$ the high magnetic field $\left(B_{0}=7.05 \mathrm{~T}\right)$ induced intense magnetic dipolar interactions between aggregated 35 USPIOs and amplified their clustering. ${ }^{25}$ Their attraction and adhesion favoured by the dehydrated polymer layer at temperatures above the LCST increased both the size and the density of the clusters (thus their iron oxide load $\Phi_{\text {intra }}$ ). This phenomenon explains why $r_{2}$ finally raised well above the values 40 at $300 \mathrm{MHz}$ of well dispersed uncoated USPIOs.

To conclude on this part, the behaviour of the USPIOs coated by thermo-sensitive poly(ether)amine chains with temperature and frequency appeared to be rather complex at first sight, but can still be interpreted by current models of $r_{1}$ and $r_{2}$ relaxivities. ${ }_{45}$ In practice, these variations of $r_{1}$ and $r_{2}$ with temperature can be turned into an advantage to efficiently modulate the contrast of MR images as a function of temperature, as shown in the next and final part of this study.

\section{${ }_{50}$ Properties as thermo-sensitive MRI contrast agent}

To show the interest of thermo-sensitive polymer coated USPIOs for MRI thermometry, images of tubes filled with this sample and with the initial TEPSA-coated control were taken on a low-field (Fig. 7) and a high-field (Fig. 8) MRI scanners, the temperature ${ }_{55}$ being varied externally from 15 to $50^{\circ} \mathrm{C}$ with a circulating bath.
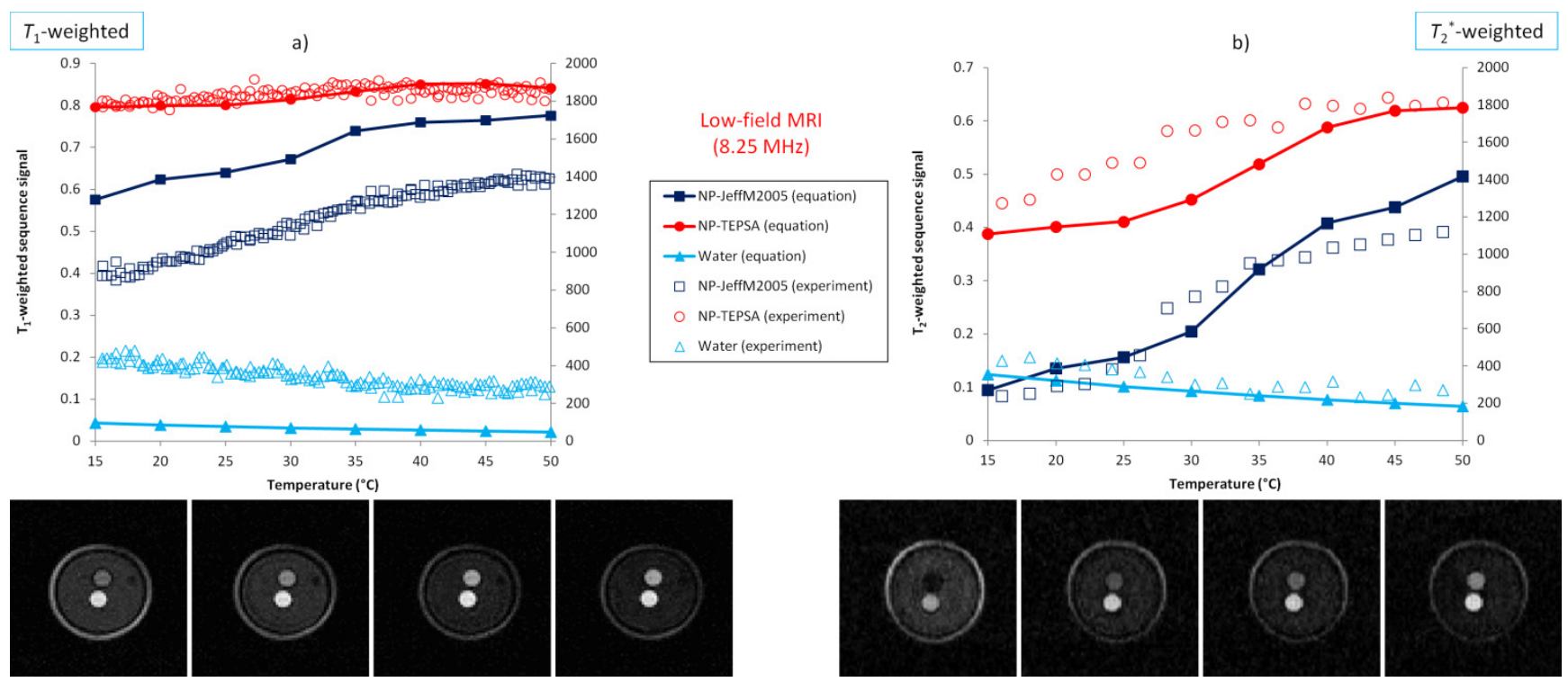

Fig. 7 Images taken on the low-field MRI scanner $(8.25 \mathrm{MHz}, 0.194 \mathrm{~T})$ at increasing temperatures from 15 to $50^{\circ} \mathrm{C}$ with a) the $T_{1}$-weighted sequence $\left(T R=100 \mathrm{~ms} T E=2.8 \mathrm{~ms}\right.$ flip angle $\left.=70^{\circ}\right)$ and b) the $T_{2}{ }^{*}$-weighted sequence $(T R=300 \mathrm{~ms} T E=12 \mathrm{~ms}), 160 \times 160 \mathrm{~mm}^{2}$ field of view, $128 \times 128 \mathrm{matrix}, 7 \mathrm{~mm}$ 60 slice thickness. The external light grey circle was ascribed to a perfusion MRI contrast of the water circulating in the double-wall of the glass chamber (diameter $50 \mathrm{~mm}$ ) as compared to water at rest inside the chamber (dark grey). The tube at the upper position was filled with Jeffamine ${ }^{\circledR} \mathrm{M}-2005$ grafted USPIOs $\left(1.1 \mathrm{mM}_{\mathrm{Fe}}\right)$ and the tube at the bottom position with the TEPSA-coated control $\left(0.8 \mathrm{mM}_{\mathrm{Fe}}\right)$. The USPIOs exhibited a positive contrast (signal above the level of pure water) on all MR images except with the $T_{2}{ }^{*}$-weighting (b) for the USPIOs grafted with the chains below their LCST $\left(15-25^{\circ} \mathrm{C}\right)$. The open markers show experimental signals. The closed markers and the solid lines represent theoretical predictions using Eq. (5) with the experimental 65 values of $T_{1}, T_{2}^{*}, T E$ and $T R$. In the case of the Jeffamine ${ }^{\circledR} \mathrm{M}-2005$ grafted USPIOs, a linear regression of the experimental signal (normalised to the initial value at $15^{\circ} \mathrm{C}$ ) versus temperature leads to slopes of $+1.9 \% /{ }^{\circ} \mathrm{C}$ and $+16.6 \% /{ }^{\circ} \mathrm{C}$ respectively for the $T_{1}$ - and the $T_{2}{ }^{*}$-weighted sequences, with correlation coefficients $R=0.98$ and $R=0.97$, respectively. MRI cross-sections at the bottom line illustrate the variations of the signal plotted on the curves. 
As the first striking feature, the low-field MR images (Fig. 7) showed a positive contrast brought by the TEPSA-coated USPIOs (increase of the signal level compared to pure water) with both the $T_{1}$-weighted and the $T_{2}{ }^{*}$-weighted sequence utilised. This can 5 be easily interpreted by a $r_{2} / r_{1}$ ratio maintained at a low value $\sim 1.5$ at all temperatures (varying slightly in fact from 1.8 at $25^{\circ} \mathrm{C}$ to 1.3 at $45^{\circ} \mathrm{C}$ ), demonstrating a perfect dispersion state of the USPIOs coated with the TEPSA silane. As comparison, USPIOs grafted with Jeffamine ${ }^{\circledR}$ M-2005 chains also exhibited positive 10 contrast with the $T_{1}$-weighted sequence on the $8.25 \mathrm{MHz}$ MRI scanner, but with a lower signal even at slightly higher iron concentration, as ascribed to a larger $r_{2} / r_{1}$ ratio. But as this ratio transited from a value $3.45 \pm 0.35$ below the LCST to $2.7 \pm 0.2$ above it (Table 2), the signal of a region of interest (ROI) centred 15 on the sample tube increased from a level $\sim 900$ at $15^{\circ} \mathrm{C}$ to $\sim 1400$ at $50^{\circ} \mathrm{C}$ (Fig. $\left.7 \mathrm{a}\right)$. Over the same temperature range, the control

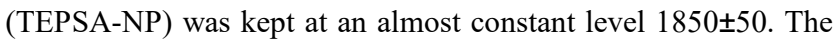
thermo-sensitive signal of the Jeffamine ${ }^{\circledR}$ M-2005 coated USPIOs was even more spectacular with the $T_{2}{ }^{*}$-weighted sequence (Fig. $207 \mathrm{~b}$ ). The sample exhibited indeed a contrast sign reversal at the exact LCST value, meaning that the curve of signal vs. temperature crossed the water baseline, nearly constant at $335 \pm 75$.

In other words, the sample tube appeared at first on the images 25 darker than pure water at low temperature, before becoming much brighter above the LCST of the polymer. The level measured in the ROI of the poly(ether)-coated USPIOs started from $\sim 190$ at $14^{\circ} \mathrm{C}$ and raised up to $\sim 1100$ at $50^{\circ} \mathrm{C}$ (Fig. $7 \mathrm{~b}$ ), meaning an increase by $\sim 600 \%$ within $36^{\circ} \mathrm{C}$ temperature change.

30 In the meanwhile, the control TEPSA-coated USPIOs showed only a moderate increase (by less than $40 \%$ ) from $\sim 1300$ at $14^{\circ} \mathrm{C}$ to $\sim 1800$ at $50^{\circ} \mathrm{C}$. To interpret such a really unusual behaviour compared to classical $T_{1}$ and $T_{2}$ MRI contrast agents, we computed the signal levels by the approximated solution of Bloch 35 equations that is found in most MRI textbooks:

$$
S_{\mathrm{MRI}} \propto \rho_{\mathrm{H}}\left(1-e^{-T R / T_{1}}\right) \cdot e^{-T E / T_{2}}
$$

This estimate of the MRI signal is proportional to the volume density of the protons $\rho_{\mathrm{H}}$ and to the product of the longitudinal magnetisation recovered after the repetition time $T R$ with the 40 transverse magnetisation remaining after the echo time $T E$. The $S_{\text {MRI }}$ calculated with experimental $T_{1}$ and $T_{2}^{*}$ are represented for both pulse sequences by the filled data points on Fig. 7 and their numerical values are provided on Table 2 on an un-dimensioned scale (on which the signal of pure water is respectively 0.025 and ${ }_{45} 0.072$ for the $T_{1}$ and the $T_{2}{ }^{*}$-weighted sequences with $T_{1}=T_{2} \approx 4 \mathrm{~s}$ ). The matching of the levels determined experimentally on the different ROIs of the images by this rather crude theoretical formula is impressively good. In particular the relative values of the polymer-coated and the control USPIOs are well estimated at 50 all temperatures, especially for the $T_{2}{ }^{*}$-weighted sequence (Fig. $7 \mathrm{~b}$ ), the value of the polymer-coated USPIOs being slightly overestimated by Eq. (5) for the $T_{1}$-weighted sequence (Fig. 7a). MRI cross-sections at the bottom of Figure 7 illustrate the variations of the signal plotted on the curves. For the two sequences $\left(T_{1}\right.$ - and ${ }_{55} T_{2}{ }^{*}$-weighted), the bottom tube containing control TEPSA-NPs appears much brighter than the water around ( $T_{1}$ effect) and shows a weak signal increase with temperature. On the opposite side, it is only with the $T_{2}{ }^{*}$-weighted sequence that the tube with Jeffamine ${ }^{\circledR}$ M-2005 coated NPs starts from a level darker than ${ }_{60}$ pure water, progressively rising up with temperature, crossing the water level near the LCST and then becoming much brighter at elevated temperatures. The water circulating in the double-wall of the water jacket containing the tubes appears always brighter than the water at rest just around the tubes, as ascribed to the 65 migration velocity of the corresponding protons.

Table 2 Longitudinal $\left(T_{1}\right)$ and transverse $\left(T_{2}^{*}\right)$ proton relaxation times for Jeffamine ${ }^{\circledR}$ M-2005 grafted USPIOs (NP-Jeff2005) and a TEPSA-control (NP) enabling to compare the experimental signals of regions of interest on images on the low-field MRI scanner to the levels estimated from the approximated solution Eq. (5) of the Bloch equations with the echo time (TE) and the repetition time (TR) of the $T_{1}$-weighted and the $T_{2}{ }^{*}$-weighted spin echo sequences.

\begin{tabular}{|c|c|c|c|c|c|c|c|c|c|c|c|c|c|c|}
\hline \multirow{3}{*}{$\mathrm{T}\left({ }^{\circ} \mathrm{C}\right)$} & \multirow{3}{*}{\multicolumn{2}{|c|}{$\begin{array}{c}r_{1}{ }^{a} \quad r_{2}^{* b} / r_{1}^{a} \\
\mathrm{~s}^{-1} \cdot \mathrm{mM}_{\mathrm{Fe}}{ }^{-1}\end{array}$}} & \multirow{2}{*}{\multicolumn{2}{|c|}{$\begin{array}{c}T_{1}(\mathrm{NP}) T_{2}^{*}(\mathrm{NP}) \\
0.8 \mathrm{mM}_{\mathrm{Fe}}\end{array}$}} & \multirow{2}{*}{\multicolumn{2}{|c|}{$\begin{array}{c}T_{1}\left(\mathrm{NP}-T_{2}^{*} \text { (NP- }\right. \\
\text { Jeff2005)Jeff2005) } \\
1.1 \mathrm{mM}_{\mathrm{Fe}}\end{array}$}} & \multicolumn{4}{|c|}{$\begin{array}{l}T_{1} \text {-weighted sequence on low-field MRI } \\
\left(T R=100 \mathrm{~ms} T E=2.8 \mathrm{~ms} \text { flip angle }=70^{\circ}\right)\end{array}$} & \multicolumn{4}{|c|}{$\begin{array}{l}T_{2}{ }^{*} \text {-weighted sequence on low-field MRI } \\
(T R=300 \mathrm{~ms} T E=12 \mathrm{~ms})\end{array}$} \\
\hline & & & & & & & NP 0. & $\mathrm{mM}_{\mathrm{Fe}}$ & NP-Jeff & $1.1 \mathrm{mM}_{\mathrm{Fe}}$ & NP 0 & $\mathrm{nM}_{\mathrm{Fe}}$ & NP-Jeff & $1.1 \mathrm{mM}_{\mathrm{Fe}}$ \\
\hline & & & $\mathrm{ms}$ & $\mathrm{ms}$ & $\mathrm{ms}$ & $\mathrm{ms}$ & $S_{\mathrm{MRI}}{ }^{c}$ & $S_{\mathrm{MRI}}^{d}$ & $S_{\mathrm{MRI}}^{c}$ & $S_{\mathrm{MRI}}^{d}$ & $S_{\mathrm{MRI}}{ }^{c}$ & $S_{\mathrm{MRI}}{ }^{d}$ & $S_{\mathrm{MRI}}{ }^{c}$ & $S_{\mathrm{MRI}}^{d}$ \\
\hline 15 & 56.4 & 3.2 & 20.2 & 12.7 & 16.0 & 5.1 & 1804 & 0.80 & 875 & 0.57 & 1300 & 0.39 & 213 & 0.09 \\
\hline 20 & 47.5 & 3.2 & 22.1 & 13.1 & 19.0 & 6.0 & 1823 & 0.80 & 969 & 0.6 & 1428 & 0.40 & 292 & 0.13 \\
\hline 25 & 39.0 & 3.6 & 23.7 & 13.5 & 23.1 & 6.5 & 1828 & 0.80 & 1053 & 0.64 & 1490 & 0.41 & 420 & 0.16 \\
\hline 30 & 32.4 & 3.7 & 25.8 & 15.1 & 27.8 & 7.6 & 1846 & 0.81 & 1148 & 0.67 & 1663 & 0.45 & 772 & 0.20 \\
\hline 35 & 29.7 & 2.9 & 28.2 & 18.3 & 30.3 & 10.6 & 1858 & 0.83 & 1269 & 0.74 & 1699 & 0.52 & 959 & 0.32 \\
\hline 40 & 24.7 & 2.7 & 30.4 & 22.6 & 36.4 & 13.4 & 1856 & 0.85 & 1290 & 0.76 & 1796 & 0.59 & 1033 & 0.41 \\
\hline 45 & 23.5 & 2.6 & 32.8 & 25.0 & 38.3 & 14.5 & 1880 & 0.85 & 1362 & 0.76 & 181 & 0.62 & 1090 & 0.44 \\
\hline 50 & 22.1 & 2.5 & 35.7 & 25.5 & 40.8 & 17.1 & 1899 & 0.84 & 1401 & 0.78 & 1814 & 0.62 & 1118 & 0.50 \\
\hline
\end{tabular}

${ }^{a}$ measured at $8.25 \mathrm{MHz}$ by FFC; ${ }^{b}$ measured on the low-field MRI at $0.194 \mathrm{~T} ;{ }^{c}$ measured experimentally (arbitrary units); ${ }^{d}$ calculated by Eq. (5) (no unit). 
a)

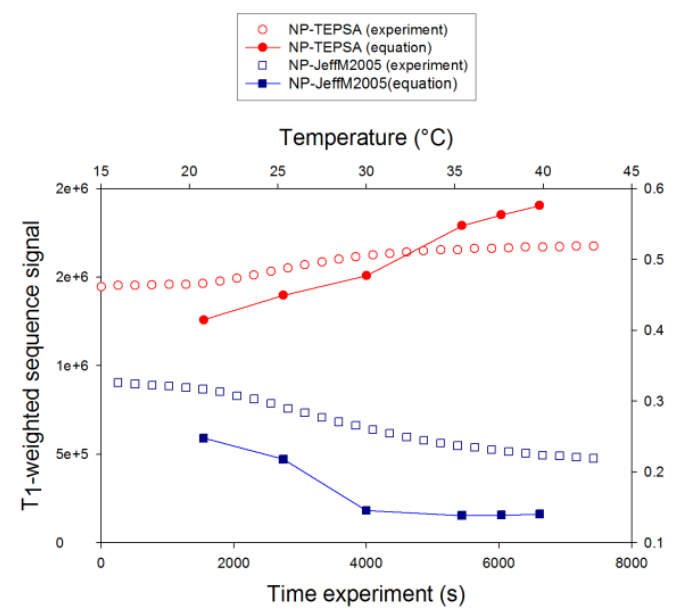

b)

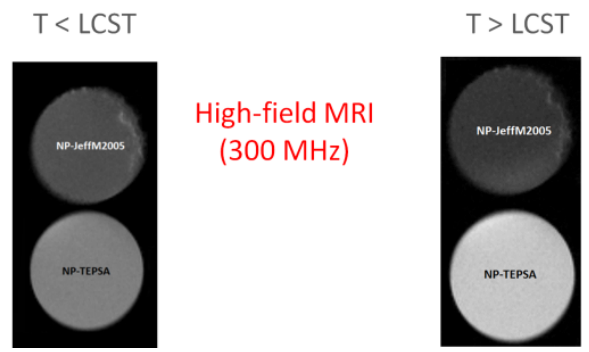

Fig. 8 a) Signal levels and b) images taken on the high-field MRI scanner $(300 \mathrm{MHz}, 7.05 \mathrm{~T})$ at increasing temperatures from 21 to $40^{\circ} \mathrm{C}$ with a $T_{2}{ }^{*}$-weighted sequence $(T R=1000 \mathrm{~ms} T E=8.5 \mathrm{~ms}), 25.6 \times 25.6 \mathrm{~mm}^{2}$ field of 5 view, $256 \times 256$ matrix, and $2 \mathrm{~mm}$ slice thickness.

An analogous analysis was undergone for the high-field MRI images (Fig. 8). In that case the $r_{2} / r_{1}$ ratios were much higher, respectively $\sim 48$ for the TEPSA-NP and $\sim 116$ for the Jeffamine ${ }^{\circledR}$ M-2005 grafted USPIOs at $10^{\circ} \mathrm{C}$. But whereas $r_{2} / r_{1}$ decreased to $10 \sim 24$ at $40^{\circ} \mathrm{C}$ for the control NP, it raised up to $\sim 286$ for the poly(ether)-coated USPIOs at $40^{\circ} \mathrm{C}$, giving rise to an increase of the signal (positive contrast) in the former case and a decrease (negative contrast) in the latter case. This high $r_{2} / r_{1}$ was certainly ascribed to an important clustering of the Jeffamine ${ }^{\circledR}$ M-2005 15 grafted USPIOs under a magnetic field of $7.05 \mathrm{~T}$. This means that a thicker and better repelling polymer corona would be absolutely necessary to achieve positive MRI contrast enhancement at such high field, especially in highly saline biological buffers. Since charged nanoparticles injected in blood plasma are immediately 20 recognised by proteins of the immune system (opsonins), ${ }^{\mathbf{2 6}}$ the clinical translation to thermo-sensitive USPIOs providing positive MRI contrast in vivo would necessitate a pure steric repulsion (stealth effect), which is out of the scope of the present study.

\section{Conclusions}

${ }_{25}$ Ultra-small superparamagnetic iron oxide (USPIO) nanoparticles were synthesised by alkaline coprecipitation in polyol, coated with a carboxy-silane and grafted by amide bond coupling with two commercial poly(ether)amines (Jeffamine ${ }^{\circledR} \mathrm{M}-2005$ and M2070) of different compositions in EO and PO units. The aim was 30 to decipher the influence of a hydrophilic or a hydrophobic shell wrapping the iron oxide core on longitudinal $\left(r_{1}\right)$ and transverse $\left(r_{2}\right)$ relaxivities, which determine their potential use as contrast agents for MRI. The relaxometric properties of USPIOs grafted with thermo-sensitive polymers were studied at four frequencies, 35 on a low-field MRI scanner at $8.25 \mathrm{MHz}$, on a high-field MRI scanner and on a NMR spectrometer at $300 \mathrm{MHz}$, and on two relaxometers at frequencies 20 and $60 \mathrm{MHz}$ close to those of 0.5 and $1.5 \mathrm{~T}$ clinical MRI scanners currently found in hospitals (21.3 and $63.9 \mathrm{MHz}$ respectively). Except at $300 \mathrm{MHz}$, all the $r_{1}$ and $r_{2}$ 40 values decreased markedly above the LCST of the chains, which could be reached only with Jeffamine ${ }^{\circledR} \mathrm{M}-2005$ since Jeffamine ${ }^{\circledR}$ M-2070 exhibited a much higher LCST. The relaxometric data were interpreted within the Outer Sphere model by the formation above the LCST of a hydrophobic coating wrapping the iron 45 oxide cores, hence preventing water molecules to directly be in contact with the iron oxide surface, which lowered the interaction between the proton spins and the magnetic moments of the USPIOs. The $r_{2} / r_{1}$ ratios were kept at a low value (except at high magnetic field), demonstrating that the polymer corona was ${ }_{50}$ sufficiently repelling to prevent USPIOs' aggregation in water. This characteristics of the NMRD profiles were turned into positive contrast enhancement on the low-field MRI scanner, not only for the $T_{1}$-weighted sequence, but also for the $T_{2}{ }^{*}$-weighted one, once the LCST was reached. In that case, the signal ${ }_{55}$ measured on a sample tube at $1.1 \mathrm{mM}_{\mathrm{Fe}}$ was found nearly linear with temperature in the $15-50^{\circ} \mathrm{C}$ range. This finding offers the possibility of non-invasive detection by MRI of localised temperature changes or gradients within the body, for instance during any kind of hyperthermia treatment for cancer catabolism.

${ }_{60}$ There are three different ways to map temperature by MRI. ${ }^{27}$ The first idea was to use the Arrhenius-type law of the spinlattice relaxation time $T_{1}$ of water and tissues $v s$. temperature, ${ }^{28}$ but it suffers from inaccuracy due to weak dependence $(\sim 1 \%$ per ${ }^{\circ} \mathrm{C}$ ) and poor linearity of the signal (linear regression coefficient $\left.{ }_{65} R<0.8\right) .{ }^{27}$ Therefore a more sensitive alternative was proposed, ${ }^{29}$ relying on the measurement by diffusion-weighted MRI of the diffusion coefficient of water molecules, which varies by $2.4 \%$ per ${ }^{\circ} \mathrm{C}$. However $D$-weighted MRI is delicate and prone to body motion artefacts. ${ }^{27}$ This is why the current method implemented 70 on most medical MRI scanners is signal phase mapping, which converts the chemical shift of proton resonance frequency (PRF), that varies by $-0.01 \mathrm{ppm} /{ }^{\circ} \mathrm{C}$, into a phase difference changing by $\sim 10^{\circ}$ per ${ }^{\circ} \mathrm{C}$ in a perfect linear manner $(R \sim 0.99) .{ }^{30}$ Both diffusion MRI and phase mapping lead to a precision of $\pm 0.5^{\circ} \mathrm{C}$, but these 75 two techniques require rather complex algorithms to get rid of artefacts such as body motions and to convert the signal into temperature information. Other methods using thermo-sensitive liposomes loaded with paramagnetic ions ${ }^{31,32}$ or chemical shift agents ${ }^{33}$ were described. But the signal was not linear and varied 80 abruptly near the melting temperature of the lipids, so that their response was rather on/off than a graduated scale to build a thermometer. In the present study, the signal of the poly(ether)coated USPIOs with the $T_{2}{ }^{*}$-weighted sequence on the low-field MRI scanner (Fig. 7 b) varied by $16.6 \%$ per ${ }^{\circ} \mathrm{C}$ (or by $100 \%$ every ${ }_{85} 6^{\circ} \mathrm{C}$ ), so that the raw signal of the image (without any data treatment) increased by $600 \%$ when temperature was increased from $14-15^{\circ} \mathrm{C}$ to $48-50^{\circ} \mathrm{C}$ with a linear regression coefficient $R \sim 0.97$ and perfect reversibility when temperature was decreased back. This study proved the concept in vitro (i.e. in tubes) of MRI 90 thermo-sensitive positive contrast agents with a sensitivity (in \% 
variation $/{ }^{\circ} \mathrm{C}$ ) potentially one order of magnitude higher than with the current methods and a good linearity of signal $(R \sim 0.97)$ in the medical temperature range, which are prerequisites to build an absolute thermometer.

5 The next step in further studies will be to modify these temperature-responsive positive MRI contrast agents so that they can work also in vivo: in particular the challenge will consist in improving the stealth behaviour of the polymer corona so that it efficiently prevents the aggregation of the USPIOs in high 10 salinity buffers supplemented with blood plasma proteins, while maintaining temperature responsiveness of the coating. Biopolymers with some characteristic transition temperature (e.g. secondary structure melting) might be the best candidates to be grafted onto USPIOs and to achieve the in vivo translation of the 15 paradigm evidenced by the present in vitro study.

\section{Abbreviations}

EO, ethylene oxide; PO, propylene oxide; LCST, lower critical solution temperature; NP, nanoparticle; USPIO, ultra-small superparamagnetic iron oxide nanoparticle; DLS, dynamic light scattering; NMR, nuclear 20 magnetic resonance; $r_{2}$, transverse relaxivity; $r_{1}$, longitudinal relaxivity; $T_{2}$, transverse relaxation time; $T_{1}$, longitudinal relaxation time; MRI, magnetic resonance imaging; $D_{\mathrm{h}}$, hydrodynamic diameter; APTS, (3aminopropyl)triethoxysilane; $R_{\mathrm{NMR}}$, distance of closest approach between the water protons and the superparamagnetic particle; $\Phi_{\text {intra }}$, intra-particle 25 volume fraction of magnetic materials; $M_{\mathrm{S}}$, magnetisation at saturation; $\gamma$, proton gyromagnetic factor; $\mu_{0}$, magnetic permeability of vacuum; $D$, diffusion constant of water molecules; $v_{\text {mol }}$, specific volume of the magnetic material; DI, de-ionized; TEPSA, 3-triethoxysilylpropyl succinic anhydride; PDI, polydispersity index; PALS, phase analysis light 30 scattering; TEM, transmission electron microscopy; IR, infrared; NMRD, nuclear magnetic relaxation dispersion; TGA, thermogravimetric analysis; CPMG, Carr Purcell Meiboom Gill; TR, repetition time; TE, echo time; PZC, point of zero charge; $v$, frequency; ROI, region of interest; EDC, 1ethyl-3-(3-dimethylaminopropyl)carbodiimide.

\section{${ }_{35}$ Notes and references}

${ }^{a}$ Department of General, Organic and Biomedical Chemistry, NMR and Molecular Imaging Laboratory, University of Mons, 19 avenue Maistriau, B-7000 Mons, Belgium. Fax: +32-65-373520; Tel: +32-65-373525; Email:sophie.laurent@umons.ac.be

$40{ }^{b}$ Center for Microscopy and Molecular Imaging, 8 rue Adrienne Bolland, B-6041 Charleroi, Belgium

${ }^{c}$ Laboratoire de Chimie des Polymères Organiques, UMR5629 CNRS / Université de Bordeaux, ENSCBP 16 avenue Pey Berland F-33607

Pessac, France. Fax: +33-5-4000-8487; Tel: +33-5-4000-3695; E-mail: 45 olivier.sandre@enscbp.fr

${ }^{d}$ Résonance Magnétique des Systèmes Biologiques, UMR 5536 CNRS /

Université de Bordeaux 146, rue Léo Saignat, F-33076, Bordeaux France

$\dagger$ Electronic Supplementary Information (ESI) available: Fig. S1: a) ${ }^{1} \mathrm{H}$ 50 NMR spectra $v s$. temperature for Jeffamine ${ }^{\mathbb{B}} \mathrm{M}-2005$, b) and M-2070 at $30 \mathrm{mg} \cdot \mathrm{mL}^{-1}$ in $\mathrm{D}_{2} \mathrm{O}$; Fig. S2: FT-IR spectra of iron oxide nanoparticles a) just after coprecipitation, and b) after coating with TEPSA; Fig. S3: Thermogravimetric analyses (TGA) of USPIOs silanized by TEPSA (red curve), and after coupling with Jeffamine ${ }^{\circledR}$ M-2005 (green curve) and M552070 (blue curve); Fig. S4: FT-IR spectra a) of the difference between the normalised spectra of USPIOs coated with TEPSA before and after grafting of Jeffamine ${ }^{\circledR} \mathrm{M}-2005$, and b) of Jeffamine ${ }^{\circledR} \mathrm{M}-2005$ alone; Fig. S5: FT-IR spectra a) of the difference between the normalised spectra of USPIOs coated with TEPSA before and after grafting of Jeffamine ${ }^{\circledR} \mathrm{M}$ 60 2070, and b) of Jeffamine ${ }^{\circledR}$ M-2070 alone; Fig. S6: NMRD profiles of the longitudinal relaxivity $v s$. proton Larmor frequency for a) TEPSA-coated USPIOs, and b) USPIOs grafted with Jeffamine ${ }^{\mathbb{B}}$ M-2070 as function of temperature; Fig. S7: a) Outer sphere radius $R_{\mathrm{NMR}}$ and saturation magnetisation $M_{\mathrm{S}} v s$. temperature for USPIOs coated by Jeffamine ${ }^{\circledR}$ M-
652070 (green markers) and TEPSA only (purple markers); Fig. S8: longitudial $r_{1}$ and transverse $r_{2}$ relaxivities of USPIOs grafted with Jeffamine ${ }^{\circledR} \mathrm{M}-2005$, normalised by the corresponding $r_{1}$ or $r_{2}$ of TEPSAcoated USPIOs, as function of temperature from 10 to $50^{\circ} \mathrm{C}$, for clinically relevant frequencies: 8.25, 20, 60, and $300 \mathrm{MHz}$. Movie1: $8.25 \mathrm{MHz} \mathrm{MR}$

70 image of Jeffamine ${ }^{\circledR}$ M-2005 NP-coated and NP-TEPSA control tubes during a temperature cycle with the $T_{1}$-weighted sequence. Movie2: 8.25 $\mathrm{MHz}$ MR image of Jeffamine ${ }^{\circledR} \mathrm{M}-2005$ NP-coated and NP-TEPSA control tubes during a temperature cycle with the $T_{2}{ }^{*}$-weighted sequence See DOI: $10.1039 / \mathrm{b} 000000 \mathrm{x} /$

75

\# The authors are grateful to Dr. Laetitia Mespouille and Dr Alain Roch for helpful discussions. The authors also thank the laboratory of Polymeric and composite Materials (Prof P. Dubois) of the University of Mons for additional TGA analysis studies. This work was performed with 80 the financial support of the FNRS, the CNRS (MI G3N "NanoBlast"), the ARC program, the ENCITE program and the RW (AGECO project), the Interuniversity Attraction Poles of the Belgian Federal Science Policy Office, the Agence Nationale de la Recherche ANR-13-BS08-0017 and the European Commission under the seventh framework within the frame 85 of ESF RNP "Precision Polymer Materials" P2M, and COST actions TD1004, TD1007, TD1402 and CM1006. The authors also would like to acknowledge the Center for Microscopy and Molecular Imaging (CMMI, supported by the European Regional Development Fund and Wallonia).

\section{Author Contributions}

90 The manuscript was written by A. H., S. L. and O. S. through contributions of all authors. A.H., D.S. and S.L. synthesized the iron oxide cores and performed the TEPSA silane grafting. A. H., J. T., C. B., O. S. and S. L. designed the polymer grafting procedure. A.H. did the polymer grafting and all the physicochemical characterisations. A. H., L. 95 V. E, R. N. M and S.L. designed and performed the proton relaxometry and high field MRI experiments. O. S., A. T., P. M. and S. M. performed and interpreted the low field MRI experiments. All authors have given approval to the final version of the manuscript.

1001 S. Laurent, J. Bridot, L. Vander Elst, and R. N. Muller, Future Med. Chem., 2010, 2, 427-449 ; S. Laurent, D. Forge, M. Port, A. Roch, C. Robic, L. Vander Elst, and R. N. Muller, Chem. Rev., 2008, 108, 2064-2110; A. K. Gupta and M. Gupta, Biomat., 2005, 26, 39954021 ; Q. A. Pankhurst, J. Connolly, S. K. Jones, and J. Dobson, J. Phys. D: Appl. Phys., 2003, 36, R167-R181; S. Mornet, S. Vasseur, F. Grasset, E. Duguet, J. Mater. Chem., 2004, 14, 2161-2175; Q. A. Pankhurst, N. K. T. Thanh, S. K. Jones, and J. Dobson, J. Phys. D: Appl. Phys., 2009, 42, 224001.

2 S. Laurent, S. Boutry. I. Mahieu, L. Vander Elst, and R. N. Muller, 110 Cur. Med. Chem., 2009, 16, 4712-4727; S. Laurent, L. Vander Elst, and R. N. Muller, "Encyclopedia of Magnetic Resonance", R. K. Harris and R. Wasylishen Eds., John Wiley: Chichester 2009; Y. Gossuin, P. Gillis, A. Hocq, Q. L. Vuong, and A. Roch, WIREs Nanomed. Nanobiotechnol., 2009, 1, 299-310.

1153 U. I. Tromsdorf, O. T. Bruns, S. C. Salmen, U. Beisiegel, and H. Weller, Nano Letters, 2009, 9, 4434-4440.

4 T. Ninjbadgar, D. F. Brougham, Adv. Funct. Mater., 2011, 21, 47694775 .

5 T. Borase, T. Ninjbadgar, A. Kapetanakis, S. Roche, R. O’Connor, C. 120 Kerskens, A. Heise, and D. F. Brougham, Angew. Chem. Int. Ed., 2013, 52, 3164-3167

6 Z. Xu, Q. Liu, J. A. Finch, Appl. Surf. Sci., 1997, 120, 269-278; M. Yamaura, R. L. Camilo, L. C. Sampaio, M. A. Macêdo, M. Nakamura, H. E. Toma, J. Magn. Magn. Mater., 2004, 279, 210-217;

125 S. Mornet, J. Portier, E. Duguet, J. Magn. Magn. Mater., 2005, 293, 127-134; A. del Campo, T. Sen, J.-P. Lellouche, I. Bruce, J. Magn. Magn. Mater., 2005, 293, 33-40; I. J. Bruce, T. Sen, Langmuir, 2005, 21, 7029-7035; W. Wu, Q. He, C. Jiang, Nanoscale Res. Lett., 2008, 3, 397-415; F. Galeotti, F. Bertini, G. Scavia, A. Bolognesi, J. Coll. \& Interf. Sci., 2011, 360, 540-547; N. Arsalania, H. Fattahia, S. Laurent, C. Burtea, L. Vander Elst, R. N. Muller, Contr. Media Mol. Imag., 2012, 7, 185-194. 
7 R. De Palma, S. Peeters, M. J. Van Bael, H. Van den Rul, K. Bonroy, W. Laureyn, J. Mullens, G. Borghs, and G. Maes, Chem. Mater. 2007, 19, 1821-1831; J. Trekker, K. Jans, H. Damm, D. Mertens, T. Nuytten, J. Vanacken, V. Moshchalkov, J. D'Haen, T. Stakenborg,

5 W. Van Roy, U. Himmelreich and L. Lagae, IEEE Trans. Magn., 2013, 49, 219-226.

8 Y. Sun, X. Ding, Z. Zheng, X. Cheng, X. Hu, and Y. Peng, Eur. Polym. J., 2007, 43, 762-772.

9 D. Forge, S. Laurent, Y. Gossuin, A. Roch, L. Vander Elst, R. N. 10 Muller, J. Magn. Magn. Mater., 2011, 323, 410-415.

10 S. Pinho, S. Laurent, J. Rocha, A. Roch, M.-H. Delville, L. Carlos, L. Vander Elst, R. N. Muller, C. Geraldes, J. Phys. Chem. C, 2012, 116, 2285-2291.

11 C. Paquet, H. W. de Haan, D. M. Leek, H.-Y. Lin, B. Xiang, G. Tian,

15 A. Kell, and B. Simard, ACS Nano, 2011, 5, 3104-3312; H. W. de Haan, C. Paquet, Magn. Res. Med., 2011, 66, 1759-1766; J. S. Riffle, N. Pothayee, S. Balasubramanian, N. Pothayee, N. Jain, N. Hu, Y. Lin, R. M. Davis, N. Sriranganathan, and A. P. Koretsky, J. Mater. Chem. B, 2013, 1, 1142-1149.

2012 Q. L. Vuong, J.-F. Berret, J. Fresnais, Y. Gossuin, and O. Sandre, Adv. Health. Mat., 2012, 1, 502-512.

13 D. Schmaljohann, Adv. Drug Del. Rev., 2006, 58, 1655-1670; A. E. Smith, X. Xu, C. L. McCormick, Prog. Polym. Sci., 2010, 35, 45-93.

14 W. Agut, A. Brûlet, D. Taton, and S. Lecommandoux, Langmuir, 2007, 23, 11526-11533.

15 S. Belbekhouche, G. Ali, V. Dulong, L. Picton, and D. Le Cerf, Carboh. Polym., 2011, 86, 304-312.

16 S. Louguet, B. Rousseau, R. Epherre, N. Guidolin, G. Goglio, S. Mornet, E. Duguet, S. Lecommandoux, and C. Schatz, Polym. Chem., 2012, 3, 1408-1417.

17 F. Azzam, L. Heux, J.-L. Putaux, and B. Jean, Biomacromol., 2010, 11, 3652-1659.

18 D. Forge, A. Roch, S. Laurent, H. Tellez, Y. Gossuin, F. Renaux, L. Vander Elst, and R. N. Muller, J. Phys. Chem. C, 2008, 112, 1917819185.

19 A. Roch, R. N. Muller, P. Gillis, J. Chem. Phys., 1999, 110, 54035411; P. Gillis, A. Roch, R. A. Brooks, J. Mag. Res., 1999, 137, 402407.

20 S. Boutry, D. Forge, C. Burtea, I. Mahieu, O. Murariu, S. Laurent, L.

40 V. Elst, and R. N. Muller, Contr. Media Mol. Imag., 2009, 4, 299 304.

21 M. V. Deshmukh, A.A. Vaidya, M. G. Kulkarni, P. R. Rajamohanan, and S. Ganapathy, Polym. , 2000, 41, 7951-7960.

22 S. Balasubramaniam, N. Pothayee, Y. Lin, M. House, R. C.

45 Woodward, T. G. St. Pierre, R. M. Davis, and J. S. Riffle, Chem. Mat., 2011, 23, 3348-3356.

23 E. D. Smolensky, H-Y. E. Park, Y. Zhou, G. A. Rolla, M. Marjanska, M. Botta, and V. C. Pierre, J. Mater. Chem. B, 2013, 1, 2818-2828.

24 M. Holz, S. R. Heil, and A. Sacco, Phys. Chem. Chem. Phys., 2000, $50 \quad 2,4740-4742$.

25 N.J. Darton, A. J. Sederman, A. Ionescu, C. Ducati, R. C. Darton, L. F. Gladden, N. K. Slater, Nanotechnology, 2008, 19, 395102-395106.

26 M. P. Monopoli, D. Walczyk, A. Campbell, G. Elia, I. Lynch, F. Baldelli Bombelli, K. A. Dawson, J. Am. Chem. Soc., 2011, 133, 2525-2534.

27 W. Wlodarczyk, R. Boroschewski, M. Hentschel, P. Wust, G. Monich, R. Felix, J. Magn. Reson. Imag., 1998, 8, 165-174; B. Quesson, J. A. de Zwart, C. T.W. Moonen, J. Magn. Res. Imag., 2000, 12, 525-533.

6028 D. L. Parker, V. Smith, P. Sherldon, L.E. Crooks, L. Fussel, Med. Phys., 1983, 10, 321-325.

29 D. Le Bihan, J. Delannoy, R. L. Levin, Radiology 1989, 171, $853-$ 857.

30 Y. Ishihara, A. Calderon, H. Watanabe, Magn. Res. Med., 1995, 34,

65 814-823; J. de Poorter, Magn. Res. Med. 1995, 34, 359; K. K. Vigen, B. L. Daniel, J. M. Pauly, K. Butts, Magn. Reson. Med., 2003, 50, 1003-1010; V. Rieke, K. K. Vigen, G. Sommer, B. L. Daniel, J. M. Pauly, K. Butts, Magn. Reson. Med., 2004, 51, 1223-1231; B. Denis de Senneville, B. Quesson, C. T. W. Moonen, Int. J. Hyperthermia,
Suzuki, Y. Matsuoka, B. Keserci, Magn. Reson. Med., 2006, 56, 835843.

31 R. Salomir, J. Palussière, S. L. Fossheim, A. Rogstad, U. N. Wiggen, N. Grenier, C. T. W Moonen, J. Magn. Res. Imaging 2005, 22, 53475 540; C. Bos, M. Lepetit-Coiffé, B. Quesson, C. T. W. Moonen, Magn. Res. Med., 2005, 54, 1020-1024.

32 R. M. Davis, B. L. Viglianti, P. Yarmolenko, J-Y. Park, P. Stauffer, D. Needham, M. W. Dewhirst, Int. J. Hyperthermia, 2013, 29, 569581.

8033 S. Langereis, J. Keupp, J. L. J. van Velthoven, I. H. C. de Roos, D. Burdinski, J. A. Pikkemaat, and H. Grüll, J. Am. Chem. Soc., 2009, 131, 1380-1381. 